\title{
Los procesos de integración iberoamericanos desde la perspectiva de España en el marco de la Unión Europea (UE): los casos del SICA y MERCOSUR ${ }^{12}$
}

\author{
Ibero-american integration processes from Spain's \\ perspective within the framework of the European \\ Union (EU): the cases of SICA and MERCOSUR
}

\author{
Ricardo Martín de la Guardia ${ }^{3}$ y Guillermo Á. Pérez Sánchez ${ }^{4}$
}

Resumen: con este trabajo pretendemos acercarnos a los procesos de integración iberoamericanos en marcha desde la perspectiva de España en el marco de la Unión Europea (UE) con especial atención a los casos del Mercado Común del Sur (MERCOSUR) y del Sistema de Integración Centroamericano (SICA). Desde su ingreso en las Comunidades Europeas, España no dejó de tender puentes entre ambos hemisferios para establecer unos Acuerdos de Asociación (AdA) necesarios entre la UE y los diversos sistemas de integración iberoamericanos, proceso que finalmente fructificó con el SICA y el MERCOSUR.

Palabras clave: Integración iberoamericana y europea; España; Unión Europea (UE); MERCOSUR; SICA; Acuerdos de Asociación (AdA).

Abstract: With this research we intend to approach the Ibero-American integration processes under way from the Spanish perspective and within the framework of the European Union (EU), paying special attention to the cases of the Southern Common Market (MERCOSUR) and the Central American Integration System (SICA). Since its entry into the European Communities, Spain has not ceased to build bridges between the two hemispheres in

Doi: https://doi.org/10.24215/23142766e073

${ }^{1}$ Recibido el 29/10/2019, aceptado el 26/11/2019

${ }^{2}$ Los autores forman parte del Proyecto de Investigación «Europeísmo y redes transatlánticas en los siglos XX y XXI»: PGC2018-095884-B-C22 (Ministerio de Ciencia, Innovación y Universidades/UE-FEDER).

${ }^{3}$ Profesor catedrático de Historia Contemporánea en la Universidad de Valladolid, España y ex Director de su Instituto de Estudios Europeos (centro de Excelencia Jean Monnet)

Senior Visitor y Senior Associate Member del Centro de Estudios Europeos de Saint Antonys College, de la Universidad de Oxford, Gran Bretaña. Salvador de Madariaga Fellow del Ministerio de Educación y Cultura en el Instituto Universitario Europeo de Florencia, Italia.

${ }^{4}$ Es Doctor en Historia Contemporánea por la Universidad de Valladolid, España. Catedrático de Universidad de Historia Contemporánea, en el Departamento de Historia Moderna, Contemporánea, de América, Periodismo y Comunicación Audiovisual y Publicidad de la Universidad de Valladolid y Director de su Instituto Universitario de Estudios Europeos. 
order to establish the necessary Association Agreements (AA) between the EU and the various Ibero-American integration systems, a process that finally succeeded with SICA and MERCOSUR.

Keywords: Ibero-American and European integration; Spain; European Union (EU); MERCOSUR; SICA; Association Agreements (AA).

«[Tanto el MERCOSUR como el SICA, consideradas (a imagen y semejanza de la UE) "zonas de paz", están comprometidas con] la democracia, la seguridad jurídica, el combate a la pobreza y el desarrollo económico y social en equidad. "

Doctor don Antonio Félix López Acosa. Embajador del Paraguay.

\section{España, América y los procesos de integración regionales}

Desde el mismo momento de la independencia de España de los territorios americanos, hace ahora justamente dos siglos, se comenzó a plantear la necesaria unidad territorial hispanoamericana ${ }^{5}$. Sin embargo, los proyectos de estos pensadores, próceres o caudillos hispanoamericanos no tuvieron un gran recorrido ${ }^{6}$, y después, durante los años treinta del siglo XIX -y por más de un siglo-, la idea de la unión de la América española dejó de ser relevante. Con las independencias nacieron nuevas unidades políticas que conformaron los Estados que conocemos, lo que significó que los "padres» de las propuestas integradoras fracasaron en dotar a su nuevo impulso de un carácter verdaderamente unitivo, y dicho impulso, además, se mostró claramente insuficiente ante las fuerzas centrífugas que ellos habían alimentado, con los resultados también por todos conocidos: en efecto, el surgimiento de una pléyade de países con estructura de Estado, portadoras de un mismo idioma ${ }^{7}$ y partícipes de un mismo sustrato cultural que, en su evolución histórica, actuaron en muchos casos a espaldas unas de otras e incluso en conflicto ${ }^{8}$.

Después del fracaso unitivo en pos de la integración durante la centuria decimonónica, hubo que esperar en la práctica hasta la segunda mitad del siglo XX para encontrarnos de nuevo con esfuerzos tendentes hacia dicha integración iberoamericana ${ }^{9}$. Algunos de estos intentos están vigentes hoy en día, pero todavía lejos de forjar la Iberoamérica unida del

\footnotetext{
${ }^{5}$ Entre los impulsores de una idea de integración, aunque con características dispares y en su caso muy innovadoras, podemos citar, entre otros, a Francisco de Miranda, a los chilenos Juan Martínez de Rosas -que aspiraba a que se creara una sola Nación bajo un solo Estado- y Juan Egaña, a Bernardino Rivadavia, a Simón Bolívar, a José de San Martín, a Bernardo Monteagudo, a José Cecilio del Valle, a Lucas Alamán, a Miguel Hidalgo, a José María Morelos o a José Martí.

${ }^{6}$ Tal como ocurrió con el «Pacto General sobre Unión, Liga y Confederación Perpetua», o el «Congreso Anfictiónico de Panamá».

${ }^{7}$ Véase MUÑOZ MACHADO, Santiago, Hablamos la misma lengua. Historia política del español en América, desde la Conquista a las Independencias, Barcelona, Crítica, 2017.

${ }^{8}$ Cfr. LUCENA GIRALDO, Manuel, Naciones rebeldes. Las revoluciones de independencia latinoamericanas, Madrid, Taurus, 2010, pp. 12-13.

${ }^{9}$ Véase al respecto OTERO, Delia del Pilar, Integración Latinoamericana. Ciclos en la construcción de un proyecto fundacional, Córdoba, Alción Editorial, 2007.
} 
siglo XXI, por la tendencia general de compartimento-estanco de los proyectos de integración iberoamericanos en el último medio siglo del novecientos ${ }^{10}$.

En todo caso, y en relación con lo anterior, debemos reseñar los siguientes procesos surgidos en dicho ámbito iberoamericano: en primer lugar, la «Organización de Estados Centroamericanos» (ODECA), de 1951, que en 1963 se convirtió en el «Mercado Común CentroAmericano» (MCCA). Por el Tratado de Montevideo de 1960 nació en la década siguiente, en 1972, la "Asociación Latinoamericana de Libre Comercio» (ALALC). Por su parte, los países andinos, después de la cumbre de Bogotá de 1966, crearon tres años después el «Grupo Andino»; también debemos mencionar a la "Asociación Latino Americana de Integración» $(A L A D I)^{11}$, que en 1980 fue creada para tomar el relevo de la ALALC. En estos afanes a favor de la integración regional tomó cuerpo la "Comunidad Andina de Naciones» (CAN) que, a partir de 1980, pretendió -aunque su protocolo fundacional se firmó en 1996- reimpulsar la actuación del antiguo Grupo Andino. Dentro de este proceso general al que nos venimos refiriendo, después del acuerdo impulsado por Argentina y Brasil que dio lugar, en 1986, al «Programa de Integración y cooperación Económica» (PICE) ${ }^{12}$, se creaba en 1991, por el «Acuerdo de Asunción», el "Mercado Común del Sur» (MERCOSUR)13. Al comienzo de la

\footnotetext{
${ }^{10}$ En este sentido, véase, por ejemplo, TORRES, Jorge José, El concepto de «Integración latinoamericana». Contenido, reformulaciones y continuidades, Buenos Aires, Dunken, 2008. Sobre las causas del fracaso del proceso de integración, véase MALAMUD, Carlos, Populismos latinoamericanos. Los tópicos de ayer, de hoy y de siempre, Madrid, Ediciones Nobel, 2010, en especial, pp. 199-207 y 218-226. En relación con lo anterior, véase también PEÑA, Félix, "América latina en el mundo: regionalismo e integración», y SANAHUJA, José Antonio, "Estrategias regionales en un mundo en cambio: América Latina y la integración regional», en ARENAL, Celestino del y SANAHUJA, José Antonio (coords.), América Latina y los Bicentenarios: una agenda de futuro, Madrid, Siglo XXI y Fundación Carolina, 2010, pp. 425-450 y 451-523, respectivamente.
}

${ }^{11}$ La creación del MERCOSUR, una década después, se justificaría, precisamente, en función de lo que supuso para los procesos de integración sudamericanos ALADI.

${ }^{12}$ También conocido como «Acta de Integración y Cooperación» (AIC). Una circunstancia importante a resaltar, como señala el Dr. Antonio Félix López Acosta, embajador y ex viceministro de Relaciones Exteriores del Paraguay para Asuntos Económicos Internacionales y Negociador Nacional ante Organismos Multilaterales y procesos de Integración Regionales y subregionales, «que introduce nuevas posibilidades de integración en la América del Sur ha sido la modificación en el año 1979 en el relacionamiento entre la Argentina y el Brasil. Ambos países, desde el siglo XIX, disputaban la supremacía regional, fueron llevados a controversia en torno a la utilización de la hidroeléctrica del Paraná (...). Prevaleció al final, oportunamente, en ambos países, una posición racional ante la cuestión, convirtiéndose la confrontación en cooperación, regulada, con la intervención de Paraguay, por el acuerdo Tripartito Corpus-Itaipú, de 1979. A partir de esas modificaciones en la relaciones Argentino-Brasileñas, después de la democratización de ambos países, evolucionaron, con celeridad, para un proyecto de integración Económica y amplio entendimiento político. Al Acta de Integración y Cooperación de 1986 siguió el Acta de Integración y Cooperación de 1989, que selló la integración entre los dos países. El 10 de agosto de 1990 Uruguay presentó una solicitud formal para participar en forma directa en las negociaciones. La propuesta uruguaya fue acogida favorablemente y se invitó al Paraguay a unirse a la negociación del proyecto para la conformación de ese espacio común». «Evolución del proceso de integración del MERCOSUR», en EDICIÓN ESPECIAL: Homenaje por los 25 años de la firma del Tratado de Asunción, ADEP, Asunción, 2016, p. 30. Para Paraguay, según Aldo Centurión López, MERCOSUR significa «la más grande oportunidad para ser un país desarrollado»: La dimensión MERSOSUR. Capítulo Paraguay, Asunción. Paraguay, Fondec, 2014.

${ }^{13}$ «El 26 de marzo de 1991 se suscribió el Tratado de Asunción para la constitución del Mercado Común del Sur (MERCOSUR). Es grande el compromiso ante el futuro, porque al firmar el Tratado de Asunción se ha asumido la obligación de promover un desarrollo con justicia social en los cuatro países, y no sólo para alguno 
década de los noventa, nos encontramos con el intento de reforzar el MCCA que llevó, en 1993, a la creación del «Sistema de Integración Centroamericana» (SICA); y una década más tarde, en los inicios del siglo veintiuno, en 2004, apareció la «Alternativa Bolivariana para las Américas y el Caribe» (ALBA) ${ }^{14}$; también en 2004 nos encontramos con la denominada «Comunidad Sudamericana de Naciones» $(\mathrm{CSN})^{15}$, impulsada por los países del MERCOSUR y la CAN, y en la que además estarían Chile y otros territorios -situados en los márgenes del mundo iberoamericano- como Surinam y Guayana; y en abril de 2007, el máximo dirigente venezolano, con la pretensión de superar e incluso sustituir la CSN, logró el respaldo de los restantes dignatarios iberoamericanos presentes en la Cumbre Energética Sudamericana para impulsar la creación de la «Unión de Naciones Sudamericanas» (UNASUR) ${ }^{16}$, cuyo tratado constitutivo se firmó en Brasilia el 23 de mayo de 2008. Finalmente, debemos reseñar que a partir de 2011, en función del denominado "regionalismo abierto», se impulsó la creación la "Alianza del Pacífico " ${ }^{17}$, formalmente constituida en 2012 a través del acuerdo marco suscrito por Chile, Perú, Colombia y México.

Fue en las últimas décadas del siglo $\mathrm{XX}$, como hemos visto, cuando se dio un nuevo impulso a los procesos de integración iberoamericanos. El contexto internacional de distensión entre los bloques y la prosperidad económica de las Comunidades Europeas situaron el

o algunos de los socios.» LÓPEZ ACOSTA, A. F., "Evolución del proceso de integración del MERCOSUR», en EDICIÓN ESPECIAL: Homenaje por los 25 años de la firma del Tratado de Asunción, op. cit., p. 31.

${ }^{14}$ En ese momento ALBA fue creada para entorpecer la actuación de ALCA, esta última impulsada por Estados Unidos, que contaba, además de este país norteamericano, con Canadá, México, Chile y otros estados centroamericanos. De este modo, como sostiene Calos Malamud, parece evidente que las prácticas «populistas y hegemónicas de Venezuela y los gobiernos del ALBA han afectado los proyectos de integración regional», Populismos latinoamericanos..., op. cit., p. 197; en este sentido, véase el epígrafe «El ALBA, ¿integración bolivariana o hegemonía venezolana?», ibídem, pp. 226-232.

${ }^{15}$ En el momento de su creación los analistas del proceso de integración iberoamericano pensaron que si la CSC tuviera éxito en su consolidación «se convertiría en la segunda área integrada más grande del mundo (...). Sin embargo, debido a las diferencia de opinión entre los países miembros no se estableció ningún calendario para la integración dentro de la CSN (...). En lugar de delegar el poder a un organismo supranacional, se propuso que la coordinación política y el proceso de convergencia fueran determinados a través de cumbres intergubernamentales. De este modo, y siguiendo la intuición de otros analistas de los procesos de integración, se podría llegar a la conclusión, de que: a la luz de las serias divergencias entre estados miembros y estados asociados del MERCOSUR (...), los planes del establecimiento de la CSN parecen ser no más que fantasías políticas sin compromisos claros y serios a corto, medio y largo plazo». GÁNDARA, Pablo y BODENSTEIN, Thilo, «La Política Económica de Integración Regional en Europa y América Latina«, en BENEYTO, José María (Dir.) y ARGEREY, Patricia (Coord.), Europa y América Latina. El otro diálogo transatlántico, Biblioteca Nueva e Instituto Universitario de Estudios Europeos de la Universidad San Pablo CEU, Madrid, 2006, p. 290. En relación a lo anterior, véase también TURIENZO, Raquel, Procesos de integración en Sudamérica. Un proyecto más ambicioso: la Comunidad Sudamericana de Naciones (CSN), Instituto Universitario de Estudios Europeos de la Universidad San Pablo CEU de Madrid.

${ }^{16}$ En relación con este proceso, podemos resaltar las palabras de Carlos Malamud, según la cuales «no se sabe muy bien qué es Unasur, ¿un foro de diálogo político o un mecanismo de integración?; y en caso de despejarse la incógnita tampoco se ha aclarado demasiado que ocurrirá con el MERCOSUR y la CAN en el futuro inmediato (...)». Populismos latinoamericanos..., op. cit., pp. 233-234. En efecto, en esta amalgama de procesos están inmersos los países del MERCOSUR que también forman parte de ALADI y, como se acaba de comentar, de UNASUR (además de ser miembros de la OEA).

${ }^{17}$ El surgimiento de la Alianza del Pacífico pudo percibirse como una consecuencia de la escasa operatividad -incluso del fracaso como proyecto de integración regional- del MERCOSUR, lo cual valía también para los líderes de dicho proceso de integración, es decir, Argentina y Brasil. 
concepto de integración en el centro del debate político y económico en gran parte del continente americano. La cooperación interregional era percibida por muchos intelectuales y gobernantes como el medio más adecuado a la hora de solventar la crisis y fortalecer un modelo de crecimiento integral, capaz no solo de satisfacer las aspiraciones nacionales de mejora, sino también de dotar de competencias reales a las áreas de integración regional ${ }^{18}$.

\section{Los procesos de integración iberoamericana: el caso del SICA Un apunte sobre España y la integración iberoamericana}

La acción exterior española, enriquecida por el ingreso en las Comunidades, amplió y fortaleció su radio de acción al descubrir nuevos focos de interés mientras nutría de savia nueva a la política exterior común. Ejemplo claro de esta última afirmación se encuentra en el caso de Iberoamérica ${ }^{19}$. En principio, la Europa de los Diez no había mostrado un interés especial por aquel continente más allá de las buenas intenciones y la retórica de la ayuda al desarrollo y a la estabilidad de la democracia -o su instauración en el caso de aquellos países donde no existía. Entre 1986 y 1990, la política española sirvió de estímulo para despertar las adormecidas conciencias de Bruselas y propiciar una implicación más decidida en los asuntos iberoamericanos. En efecto, en junio de 1987 el Consejo de Ministros de Asuntos Exteriores de los Doce aceptó una estrategia de acción común que hacía suyas las propuestas españolas ${ }^{20}$.

En este sentido, y por lo que a cuestiones más prácticas se refiere, España ha sido una pieza clave en el reconocimiento comunitario de la importancia de Iberoamérica en el contexto de las relaciones externas de la Unión, un ámbito geográfico que había contado muy poco en Bruselas antes de que a ella llegara nuestro país. Algunos ejemplos son muy relevantes para comprender lo decisivo de la presencia española en negociaciones como las emprendidas con el Mercosur en diciembre de 1995 o con México que fraguó en el año 2000

\footnotetext{
${ }^{18} \mathrm{El}$ impulso a la integración económica no fue ajeno el excesivo endeudamiento externo de las economías latinoamericanas a mediados de los años ochenta. EI PIB por habitante a finales de la década apenas había variado respecto al término de la anterior, y había que escapar de la situación descrita por Osvaldo Hurtado, ex presidente de Ecuador, en una conferencia pronunciada en Buenos Aires en 1989: «Excepto en el tema de la deuda externa, no hay ninguna otra materia en la que América Latina tenga algún papel en el mundo.» HURTADO, Osvaldo, "Aspectos políticos de la integración latinoamericana», Integración Latinoamericana. BID/INTAL 153 (enero-febrero, 1990), p. 4.

${ }^{19}$ Sin embargo, la apuesta por la Comunidad Iberoamericana de Naciones, constituida el 19 de julio de 1991 en Guadalajara de México por diecinueve estados latinoamericanos además de España y Portugal, no rendiría los frutos esperados. En ella desempeñó un papel crucial la apuesta española por estrechar lazos con el Nuevo Continente y ganar presencia en aquel espacio internacional después de las transiciones democráticas operadas en la mayor parte de la región. El fundamento de una colaboración económica y cultural traspasaba el ámbito interestatal para alcanzar una auténtica acción integrada. Sin duda, la consecución más positiva de este proyecto sería las cumbres de los Jefes de Estado y Gobierno celebradas anualmente desde su fundación, en las que se hacía balance de los logros y se proponían nuevos objetivos. Sin embargo, a mediados de la década la realidad mostraba que la retórica y el aparato desplegados en las cumbres se imponían a los resultados concretos.
}

${ }^{20}$ EFPB 87/227 «Conclusions adopted by the Council ande the Represenattives of the Governments of the Member States Concerning the Relations with Latin America», Bruselas, 22 de junio de 1987. 
en un Acuerdos de Libre Comercio. Este ejemplo nos sirve para entender la actitud del Gobierno español una vez consumada la integración en las Comunidades: todos los gobiernos democráticos que siguieron a la muerte del General Franco habían considerado que las vertientes europea e iberoamericana de la política exterior eran necesariamente complementarias $^{21}$ y de ahí que la incorporación de España sirviera de revulsivo en Bruselas para intensificar los contactos con el otro lado del Atlántico. Los beneficios para fortalecer el protagonismo español fueron también recíprocos al ampliar las posibilidades de su acción exterior no sólo mediante la diplomacia nacional sino también por medio de la política específica de la Comunidad Europea hacia Iberoamérica ${ }^{22}$.

En relación con todo lo anterior, en especial con la marcha hacia la integración regional en Iberoamérica, se hace necesario una comparación con el proceso europeo: este modelo trató de arrancar, en principio, de aquellas materias que exigían una colaboración entre las partes sin menoscabar al mismo tiempo las prerrogativas estatales y, a continuación, de fortalecer los vínculos comunitarios a partir de ese núcleo de tal manera que con la paulatina profundización del proceso -es decir, con el aumento progresivo del número de materias compartidas- este se hacía irreversible. El camino recorrido por las Comunidades, primero, y por la Unión Europea, después, representa un desafío de enorme relevancia para Iberoamérica si no quiere quedar arrumbada en el curso de la globalización acelerada tras el derrumbe del sistema bipolar, ya que en el nuevo contexto las zonas económica y políticamente influyentes se presentan como potencias regionales. Para poder competir en cualquier ámbito con Estados Unidos, la UE o China y su zona de influencia, no existe otra forma que la integración.

Además, y manteniendo la perspectiva histórica, las crisis económicas o institucionales abiertas a lo largo del proceso de unificación europea no han conllevado la reformulación de todo el sistema, sino que, incluso en las más graves, siempre ha imperado la voluntad política de negociar para, una vez solventados los problemas, continuar avanzando en el proceso integrador. En este sentido, la experiencia ha mostrado que las terceras vías alternativas a la democracia liberal y a la economía capitalista no se sostienen. La apuesta decidida por la libertad de mercado no elimina la legítima disparidad de criterios sobre el Estado del bienestar y ha favorecido el reparto más equitativo de la riqueza. De hecho, el marco de la UE ha servido para impulsar el desarrollo de regiones secularmente atrasadas y erradicar las desigualdades más flagrantes. En relación con lo anterior, no está de más recordar que los países iberoamericanos disponen de un acervo cultural mucho más homogéneo que el europeo. Es esta herencia común la que podría utilizarse para facilitar el uso compartido de sus enormes recursos en la creación de un espacio con mayor cohesión interna que lime las profundas diferencias socioeconómicas entre ellos y, por supuesto, dentro de cada uno de ellos.

\footnotetext{
${ }^{21}$ Véase ARENAL, Celestino del, «La adhesión de España a la comunidad Europea y su impacto en las relaciones entre América Latina y la Comunidad Europea», Revista de Instituciones Europeas, vol. 17 (1990), pp. 329368; y también MONTALBÁN, Juan Francisco, "Los cambios en la política comunitaria hacia América Latina tras la adhesión española», Tiempo de Paz, no 24-25 (1992), pp. 107-112.

${ }^{22}$ Cfr. MARTíN DE LA GUARDIA, Ricardo, "La política europea de España después de la integración en las comunidades», Cuadernos Europeos de Deusto, no 32 (2005), p. 65.
} 


\section{Las relaciones entre las Comunidades Europeas y Centroamérica a partir de la década de 1980}

Centroamérica era un punto especialmente conflictivo en los inicios de las década de los ochenta. La caída del régimen somocista en julio de 1979 y la toma del poder a manos del Frente Sandinista, el asalto a la Embajada Española en Guatemala en enero de 1980 y la crisis política en El Salvador formaban parte de un escenario en el que la influencia estadounidense y la complejidad que entrañaba cualquier decisión alejaban las posibilidades de que se lograse una presencia activa tanto española como comunitaria ${ }^{23}$. En abril de 1983, después de un período de incertidumbre, el Gobierno de Madrid fue el primero de los de Europa Occidental en apoyar explícitamente la declaración del Grupo de Contadora, en virtud de lo cual España colaborará decididamente en la gestación o desarrollo de planes de pacificación y estabilidad del área, con notables repercusiones en todo el ámbito iberoamericano, incluido el mayor prestigio de la política española en todo el continente.

Como veremos a continuación, las Comunidades Europeas, en efecto, alcanzaron cierto protagonismo en Centroamérica al apostar decididamente por la pacificación en la zona en función de los Acuerdos de Guatemala de 1987; alentaron una mejora de las relaciones con el Pacto Andino y estuvieron presentes en Nicaragua para defender el proceso democratizador, una de cuyas consecuencias fue la celebración de elecciones libres en febrero de 1990. De hecho, ya en el programa de la política exterior del Partido Socialista Obrero Español (PSOE) figuraba como uno de sus pilares la acción exterior hacia lberoamérica, prioridad sentida con igual intensidad que la incorporación española a las Comunidades $^{24}$. El objetivo era mantener una relación estrecha con los países americanos al margen de los gobiernos de turno, aunque, evidentemente, el grado de colaboración dependería del respeto a los principios democráticos y a los derechos humanos. La idea defendida por el PSOE consistía en estimular a la Comunidad para que ésta tomara en mayor consideración a Iberoamérica y fomentara unos vínculos más sólidos en todos los campos: el económico, por supuesto, pero también el científico-técnico, cultural y educativo, entre otros.

Centrándonos en las relaciones entre las Comunidades Europeas y Centroamérica, Christopher Patten, a la sazón Comisario de Relaciones Exteriores de la Comisión Europea, señaló muy oportunamente que, a la hora de estudiar el proceso de integración centroamericano, se podía «establecer un paralelismo con el proceso de integración de la Unión Europea, cuyo punto de partida fue la voluntad de preservar la paz mediante la cooperación y la seguridad colectiva y en el que la integración económica ha sido la principal fuerza impulsora que ha llevado a la extensión de la autoridad política y jurídica por encima de las fronteras nacionales".

En todo caso, los vínculos entre las Comunidades Europeas y Centroamérica pudieron consolidarse -como ya se ha señalado-cuando, a lo largo de la década de 1980, esta región inició el camino de la paz y la reconciliación, al darse por cerrados los conflictos armados que se habían producido en la zona en las décadas anteriores (guerras civiles en El Salvador,

\footnotetext{
${ }^{23}$ Véase PIÑOL, Joan, "Las relaciones españolas en Centroamérica: el período de los Gobiernos socialistas», Afers Internacionals, no 14-15 (1988), pp. 5-40.

${ }^{24}$ Puede encontrarse un análisis exhaustivo de esta política en ARENAL, Celestino del y NÁJERA, Alfonso, La Comunidad Iberoamericana de Naciones. Pasado, presente y futuro de la política iberoamericana de España, Madrid, Cedeal, 1992, pp. 222-273.
} 
Guatemala, Nicaragua, la guerra entre el Salvador y Honduras). Sin lugar a dudas, ese «paralelismo" y el ejemplo positivo que se quería "exportar» de la integración europea influyeron en el interés de las Comunidades Europeas por la integración del istmo centroamericano. De este modo, el «compromiso» de la Unión Europea con Centroamérica, que se ha mantenido en el tiempo hasta nuestros días, tomó carta de naturaleza a partir del denominado «Diálogo de San José», puesto en marcha el 28 de septiembre de 1984. En palabras de Patten, el propósito fundamental de dicho Diálogo «era aprovechar la labor del Grupo [o Proceso] de Contadora para impulsar la paz, la democracia, la seguridad y el desarrollo social y económico en toda Centroamérica». Así las cosas, en noviembre de 1985 se firmó en Luxemburgo el «Acuerdo de Cooperación» entre las Comunidades Europeas y los países miembros del Tratado General de Integración Económica Centroamericana. Como sostienen Silvia Miranda y Roberto Echandi ${ }^{25}$, precisamente la experiencia traumática de tan reciente conflicto «y la necesidad de colaborar con el proceso de pacificación orientaron la cooperación europea en la región, que posiblemente no habría alcanzado tal magnitud si no hubiese existido dicha crisis. Esta situación ha fortalecido definitivamente los lazos entre ambas regiones y les ha permitido atender sus propios intereses». En efecto, como se señaló más arriba, el Proceso de Contadora (8 y 9 de enero de 1983), pasando por «Esquipulas I» (mayo de 1986) y “Esquipulas II» (cumbre de Presidentes de Centroamérica, 6 y 7 de agosto de 1987), Ilevó finalmente al Acuerdo de Guatemala, por el que se ponía en marcha el «Procedimiento para establecer la paz firme y duradera en Centroamérica» (firmado el 7 de agosto de 1987 por los presidentes de Costa Rica, El Salvador, Guatemala, Honduras y Nicaragua).

Al entrar en la década de 1990, el trabajo llevado a cabo en las «cumbres presidenciales» desembocó en el establecimiento de un nuevo marco político y jurídico en la integración de la región centroamericana impulsado por el denominado «Protocolo de Tegucigalpa» de 1991. De este modo, y en teniendo en cuenta que la integración centroamericana apostaba por su consolidación al transformar en 1993 el antiguo Mercado Común Centroamericano (creado en 1963) en el novedoso Sistema de Integración Centroamericano $(\mathrm{SICA})^{26}$, la Unión Europea y los países de América Central (Costa Rica, El Salvador, Guatemala, Honduras, Nicaragua y Panamá) firmaban en 1993 el «Acuerdo Marco de Cooperación» (que entró en vigor el 1 de marzo de 1999), que años después, como se demostró en los encuentros de Florencia, en 1996, y en Madrid, en 2002, influyó en la nueva orientación del «Diálogo» hacia el desarrollo sostenible y una mayor integración en la subregión centroamericana ${ }^{27}$. Fue en mayo de ese último año, cuando en el marco de la Cumbre Unión

\footnotetext{
${ }^{25}$ En la obra colectiva GRANADOS, Jaime; LIZANO, Eduardo, y OCAMPO, Fernando (Editores), Un puente para el crecimiento. Oportunidades y desafíos del Acuerdo de Asociación entre Centroamérica y la Unión Europea, banco Interamericano de Desarrollo, Academia de Centroamérica y Konrad-Adenauer-Stiftung, 2009.

${ }^{26}$ Véase a este respecto ULATE CHACÓN, Enrique y OLMOS GIUPPONI, Ma Belén, «Sistema de la Integración Centroamericana (SICA): Estructura institucional, ámbitos de actuación y perspectivas de futuro», en Cuadernos Iberoamericanos de integración, 9 (2009), 155 páginas. MURCIA, Walter, ODDONE, Nahuel, y RODRÍGUEZ VÁZQUEZ, Horacio, La integración centroamericana: orígenes, avances y desafíos, -Cuadernos de Cooperación Internacional y Desarrollo-, México, Instituto Mora. Universidad Iberoamericana, 2015. Y VV.AA., Mirada Centroamericana, Ciudad de Guatemala, Universidad Rafael Landívar. Guatemala, Universidad Centroamericana José Simeón Cañas. El Salvador, Universidad Centroamericana. Nicaragua, 2017.

${ }^{27}$ Véase en este sentido SANAHUJA, José Antonio y SOTILLO, José Ángel (coords.), Integración y desarrollo en Centroamérica. Más allá del libre comercio, Madrid, Instituto Universitario de Desarrollo y Cooperación, Universidad Complutense de Madrid. Los Libros de la Catarata, 1998.
} 
Europea-América Latina y el Caribe, Centroamérica y la Unión Europea pusieron en marcha la negociación para formalizar un «Acuerdo de Diálogo Político y Cooperación » que se firmó en Roma el 15 de diciembre de 2003.

\section{La UE y el SICA hacia el establecimiento de un Acuerdo de Asocia- ción (AdA)}

Fue entonces, en el marco de la III Cumbre entre la Unión Europea-América Latina y el Caribe, celebrada en Guadalajara en mayo de 2004, cuando ambas Partes acordaron establecer un mecanismo de evaluación conjunta con el objetivo de examinar el proceso de integración económica regional centroamericana, como paso previo al inicio de las negociaciones para un Acuerdo de Asociación (AdA). Para formalizar dicho proceso y definir sus objetivos y metodología, ambas Partes se reunieron el 19 de enero de 2005 en Bruselas con ocasión de la celebración de la XIII Comisión Mixta Unión Europea-Centroamérica. En la Cumbre Unión Europea-Centroamérica, celebrada en Viena en mayo de 2006, se reiteró el compromiso de establecer el mencionado AdA; y, al año siguiente, los días 28 y 29 de junio, las Partes en cuestión acordaron el inicio de las negociaciones en tal sentido ${ }^{28}$. La primera ronda de negociaciones para el establecimiento del AdA tuvo lugar en octubre de 2007 en San José de Costa Rica. En total se celebraron nueve rondas de negociaciones para tratar los que se consideraron los tres pilares básicos (Pilar Político, Pilar de Cooperación y Pilar Comercial) y siete reuniones técnicas comerciales. Durante las negociaciones se realizó un amplio proceso de consulta con los distintos organismos de la administración pública afectados y con los sectores productivos, académicos, organizaciones no gubernamentales y demás grupos interesados. Según los expertos del Banco Interamericano de Desarrollo, el establecimiento de este AdA con la Unión Europea podía ser considerado como el mejor «puente para el desarrollo» de Centroamérica, el «más adecuado para profundizar las relaciones comerciales entre ambas regiones, fortalecer los vínculos políticos, consolidar la cooperación europea en la región y profundizar el proceso de integración regional», y suponía al mismo tiempo tanto una oportunidad como un desafío para la región.

En mayo de 2010, en menos de tres años de trabajo, en la IV Cumbre Unión EuropeaAmérica Central celebrada en Madrid, las negociaciones para el AdA llegaron a buen puerto. En el comunicado conjunto emitido el 19 de mayo, se señalaba que en dicha Cumbre las Partes afectadas «han destacado la naturaleza fructífera de las relaciones existentes entre ambas regiones, que se ha desarrollado en el marco del Diálogo de San José, establecido en 1984, y han confirmado los puntos de vista y los compromisos manifestados en Lima el 17 de mayo de 2008». En función de lo anterior, dichas Partes celebraban la conclusión de las negociaciones y señalaban lo siguiente: «Dicho Acuerdo, que abarca todos los aspectos de las relaciones birregionales, el diálogo político, la cooperación y el comercio, constituye la manifestación más concreta de la fuerza de nuestro vínculos. Al fomentar el diálogo político y la cooperación en asuntos de interés común y al impulsar nuestro respectivos flujos comerciales e inversiones, el Acuerdo de Asociación anuncia una nueva era en las relaciones entre la Unión Europea y América Central». También se destacaba en el comunicado que

\footnotetext{
${ }^{28}$ Véase COMISIÓN EUROPEA, «Documento de estrategia regional para América Central, 2007-2013», (Marzo 2007).
} 
nos ocupa que, para las Partes, «la seguridad es uno de los aspectos prioritarios de su plan de trabajo común y en que la inseguridad plantea graves riesgos para el desarrollo humano, social y económico, y, por consiguiente, para la estabilidad democrática en América Central». En este sentido, las Partes «han estado de acuerdo en que el ejercicio efectivo de la democracia, el estado de derecho y el respeto de los derechos humanos son esenciales para la seguridad de las personas».

\section{El AdA entre la UE y el SICA}

En función de lo anterior, el 22 de marzo de 2011, los representantes de la Unión Europea y de América Central completaban el proceso de revisión legal del AdA y rubricaron los textos negociados. En palabras de la Alta Representante de la UE, Catherine Ashton, este AdA «es una prueba concreta de nuestro siempre presente compromiso con la región de Centroamérica. Nos permitirá profundizar aún más nuestro diálogo y reforzar nuestra presencia en la región, donde la UE es ya el mayor donante, inversor y socio». Por su parte, para el Comisario de Comercio de la Comisión Europea, Karel De Gucht, la firma del AdA «es un paso importante hacia la entrada en vigor de este acuerdo verdaderamente interregional. En un acuerdo ambicioso y muy amplio, que impulsará el comercio y la inversión entre las Partes, que ayudará al crecimiento y a la creación de empleo, como también a la integración regional de América Central». Formalmente, el AdA fue firmado por la Partes en Tegucigalpa, el 29 de junio de 2012 (el Parlamento Europeo lo aprobó el 11 de diciembre del mismo año), y de los tres pilares que, como sabemos, lo conforman (el de Diálogo Político, el de Cooperación y el del Comercio), el primero en entrar en vigor para la mayor parte de los países centroamericanos ha sido el Pilar del Comercio, en concreto el 1 de agosto de 2013. Como resaltó Hugo Martínez Bonilla, Secretario General del SICA, el AdA es «único en su género», además de ser "el primero que suscribe la Unión Europea de región a región», lo cual redundará en una mejor relación comercial, además de potenciar las inversiones, todo lo cual coadyuvará a impulsar el desarrollo social y, en definitiva, a mejorar de las condiciones de vida y de trabajo de los centroamericanos ${ }^{29}$. Lo anterior -en especial el carácter de ser el primer acuerdo que suscribe la Unión Europea de región a región- también fue resaltado por la Fundación Konrad-Adenauer-Stiftung en una primera valoración presentada por su oficina en Costa Rica y Panamá ${ }^{30}$.

Según los responsables del SICA, el verdadero significado del AdA se encuentra en la pujanza que se otorga a la futuras relaciones entre la Unión Europea y la región de Centroamérica, de las que se obtendrán beneficios potenciales y grandes posibilidades: «En principio, algunas de ellas incluyen aumentar las exportaciones hacia un mercado amplio, de alta capacidad de compra, sofisticado y exigente; a la vez que se espera un incremento de inver-

\footnotetext{
${ }^{29}$ Véase a este respecto CANO LINARES, Mạ Ángeles y DÍAZ-SILVEIRA SANTOS, Cintia, La acción exterior del Sistema de la Integración Centroamericana, Madrid, Editorial Dykinson, 2012.

${ }^{30}$ KONRAD-ADENAUER-STIFTUNG (Oficina en Costa Rica y Panamá), «El Acuerdo de Asociación entre Centroamérica y la Unión Europea», www.kas.de/costa-rica/es/pages/6207/Véase también a este respecto, GOBIERNO DE EL SALVADOR, Acuerdo de Asociación: ofreciendo oportunidades para el desarrollo, Documento explicativo del Acuerdo de Asociación entre Centroamérica y la Unión Europea, 2013.
} 
sión europea en nuevas empresas. Otro de los efectos que se debe esperar es el fortalecimiento y profundización de la integración Centroamericana, que sin duda nos abre las posibilidades de inducir un proceso de desarrollo más acelerado. Ello si estamos convencidos, como deberíamos estarlo, de que integrados tenemos más posibilidades de competir en este mundo globalizado que si lo hiciéramos de manera aislada» ${ }^{31}$. Ese carácter «único en su género» al que nos referíamos anteriormente, se percibe también, según Rómulo Caballeros Otero $^{32}$ (experto de PAIRCA II/GOPA), en la «dimensión integral» del AdA, es decir, "que los tres temas de la relación [políticas, de cooperación y comerciales] se encuentran íntimamente interrelacionados y el contenido de los Tres Pilares [diálogo político, cooperación y comercio] detalla esa interconexión». Ni siquiera una interpretación crítica del proceso $^{33}$ puede dejar de reconocer que dicho AdA «encaja bien con la idea de la Unión Europea de impulsar acuerdos con bloques subregionales que eventualmente puedan confluir en un gran acuerdo de alcance regional. Esto dotaría de coherencia al discurso oficial de la UE de apostar por una forma de regionalismo abierto que fortalezca los procesos de integración regional de Latinoamérica» ${ }^{34}$.

\section{Los retos del AdA en el momento presente}

En definitiva, para entender la situación presente y los retos del futuro, y siguiendo a Caballeros Otero ${ }^{35}$, podemos indicar que el AdA presenta unas características sobresalientes: «certeza jurídica», «reciprocidad», «integridad» e «institucionalidad»; unos objetivos principales a conseguir: «consolidar una relación», "desarrollar una asociación», «mejorar la cooperación birregional", «incrementar el intercambio comercial» e «impulsar la integración regional»; una estructura definida: con «una base -organización institucional-», «tres pilares -diálogo político, cooperación y comercio-» y «dos dinámicas -dimensión nacional y proyección regional-». En todo caso, para que el AdA resulté operativo y se mantenga en el tiempo, más allá de las dificultades estructurales propias de una región en desarrollo, será preciso que los países miembros del SICA extraigan de la experiencia europea el valor positivo de lo supranacional, en coexistencia con lo intergubernamental, como norma suprema del proceso de integración ${ }^{36}$.

\footnotetext{
${ }^{31}$ Véase, por ejemplo, MIRANDA, Otilio, Derecho Comunitario de América Central, Managua, Universidad Centroamericana, 2010.

32 "Centroamérica: los retos del Acuerdo de Asociación con la Unión Europea», en Estudios y perspectivas CEPAL (Sede Subregional México-, 102 (2008), 68 páginas.

${ }^{33}$ Por ejemplo, la expresada por BIDAURRATZAGA, Eduardo y ZABALO, Patxi, "Efectos potenciales del Acuerdo de Asociación con la Unión Europea sobre el desarrollo de Centroamérica", http://xivrem.ujaen.es/wp-content/uploads/2012/05/80-R-043M517.pdf

${ }^{34}$ Para un estudio comparado de ambos procesos, remitimos a la obra de MEJíA HERRERA, Orlando José, La Unión Europea como modelos de integración: análisis comparativo del Sistema de la Integración Centroamericana, León, Editorial Universitaria, UNAN-León, 2008.

35 "Centroamérica: los retos del Acuerdo de Asociación con la Unión Europea», art. cit.

${ }^{36}$ Véase en relación a lo anterior OLMOS GIUPPONI, María Belén y RUBIO RíOS, Luis Arnoldo (eds.), La adopción de políticas en el sistema de la Integración Centroamericana. Propuestas para su perfeccionamiento a la luz de la experiencia europea, Madrid, Plaza y Valdés Editores, 2011.
} 


\section{Los procesos de integración iberoamericanos: el caso del MERCOSUR}

\section{MERCOSUR: la potencialidad teórica del Tratado de Asunción}

En el Tratado de Asunción de marzo de 1991, donde se acordó la creación del MERCOSUR, se afirmaba que «la ampliación de las actuales dimensiones de [los] mercados nacionales, a través de la integración, constituye condición fundamental para acelerar [los] procesos de desarrollo económico con justicia social». El documento añadía que el programa diseñado contemplaba «la evolución de los acontecimientos internacionales, en especial, la consolidación de grandes espacios económicos y la importancia de lograr una adecuada inserción internacional para sus países ${ }^{37}$. Tras el final de la Guerra Fría, parecía evidente que los mandatarios de Brasil, Argentina, Uruguay y Paraguay tomaban conciencia de la necesidad de dar una respuesta conjunta e integrada a la globalización económica si querían afrontar el nuevo siglo con garantías de éxito.

El Tratado de Asunción aspiraba a constituir un auténtico mercado común, para lo cual el Programa de Liberación Comercial era uno de sus mecanismos principales. La reducción arancelaria progresiva aplicada a los intercambios comerciales entre sus miembros debía concluir a finales del año 1994, fecha fijada para constituir una zona de libre comercio, pero en la práctica estas perspectivas no pudieron cumplirse hasta justo cuatro años más tarde, el 31 de diciembre de 1998. Con todo, el ideal de un mercado común tendría que esperar todavía más, ya que los Anexos del Tratado no contemplaban los instrumentos necesarios para concretarlo: faltaba cómo coordinar las distintas políticas macroeconómicas de los estados, aceptar la libre circulación de capital y personas, y poner en marcha una legislación común, entre otros aspectos.

Así las cosas, el objetivo fundamental que nos ocupa es contribuir al debate científico acerca de las dificultades, problemáticas y perspectivas con relación al MERCOSUR, en clave comparada con el proceso de integración europeo ${ }^{38}$, y a la evolución del largo proceso de negociación entre ambos actores regionales para alcanzar un Acuerdo de Asociación (AdA). En relación con lo ya apuntado, bien se puede afirmar que el MERCOSUR mantiene ahora mismo tanta actualidad como en el momento de su creación por el Tratado de Asunción de 1991, hace ya más de veinticinco años ${ }^{39}$. En efecto, de repente hemos podido observar cómo

\footnotetext{
${ }^{37}$ Torres, Jorge José, El concepto «integración latinoamericana»..., op. cit., p. 53.

${ }^{38}$ Para acercarse a dicho estudio en clave comparada desde el punto de vista iberoamericano. Véase, entre otras aportaciones, SOTO, Alfredo Mario y GONZÁLEZ, Flavio Floreal, Manual de Derecho de la Integración, Buenos Aires, La Ley, 2016, en especial, los epígrafes debidos a GONZÁLEZ, Flavio F., «Unión Europea», pp. 49-171, "Mercosur», pp. 217-328; y RECONDO, Gregorio (Coordinación y Prólogo), MERCOSUR. Una historia común para la integración, Tomo I y Tomo II, Asunción, Paraguya, Multibanco SAECA, 2000. Véase también BENEGAS CRISTALDO, Gladys S., A la búsqueda de un Mercado Común: MERCOSUR. Creación de Comercio, Desviación de Comercio e Implicaciones de Políticas Públicas, Asunción, Paraguay, Centro de Publicaciones de la Universidad Católica Nuestra Señora de la Asunción, 1994.

${ }^{39}$ La firma del Tratado tuvo lugar el 26 de marzo de 1991en la sede del Banco Central del Paraguay. Los firmantes del mismo fueron los presidentes de Argentina, Carlos Saúl Menem; de Brasil, Fernando Collor; de Paraguay, Andrés Rodríguez, y de Uruguay, Luis Alberto Lacalle. En palabras del canciller nacional, embajador Eladio Loizaga: "Para Paraguay siempre ha sido un motivo de orgullo que la firma del Tratado del Mercosur se realizara en Asunción, pues coincide con el carácter de nuestra capital como "Madre de Ciudades". Por eso, cuando se habla del Mercosur resuena gratamente el título del Tratado de Asunción. Mensaje «Por los 25 años del Mercosur».
} 
el MERCOSUR se ha hecho presente de nuevo en las agendas diplomáticas y en los medios de comunicación iberoamericanos, pero también europeos en general y de otras latitudes. Lo anterior venía justificado en función de los retos asumidos por el presidente argentino, Mauricio Macri, quien, después de su elección en 2015, no dudaba en presentarse como el nuevo líder regional, empeñado en impulsar el cambio de rumbo en el ámbito del MERCOSUR. En relación con lo anterior, aprovechando su visita a Paraguay (el 25 de noviembre de 2015), el ministro español de Asuntos Exteriores, y teniendo en cuenta que en ese momento Paraguay ejercía la presidencia rotatoria del MERCOSUR, se comprometió a pulsar el cambio de actitud que se venía produciendo en países como Brasil, y ahora también Argentina, para impulsar los vínculos y acuerdos -en vía de tramitación- entre el MERCOSUR y la UE.

Como hemos visto, la actual agenda política sitúa al MERCOSUR como actor de gran relevancia, ya que, en palabras del embajador Eladio Loizaga, ministro de Asuntos Exteriores del Paraguay, en nuestros días dicho proceso de integración «es mucho más que un proyecto económico consolidado. Hemos logrado avanzar en importantes temas como las cuestiones sociales y políticas, en una colaboración estrecha en campos tales como la salud, la educación, la cultura, las migraciones, entre otros. Asimismo, es innegable el aporte del Mercosur para la consolidación democrática y la preservación del orden constitucional de nuestras naciones ${ }^{40}$; aunque, curiosamente, sobre esto último no se alude en el texto del Tratado de Asunción, lo que a la postre, en nuestra opinión, debilitó el proceso de integración al restarle esencia unitiva por la falta de referencia a valores fundamentales. En efecto, en lo que pudiéramos considerar el Preámbulo del Tratado, solo se dice lo siguiente: «CONSIDERANDO que la ampliación de las actuales dimensiones de sus mercados nacionales, a través de la integración, constituye condición fundamental para acelerar sus procesos de desarrollo económico con justicia social», "CONSCIENTES de que el presente Tratado debe ser considerado como un nuevo avance en el esfuerzo tendente al desarrollo en forma progresiva de la integración de América Latina, conforme al objetivo del Tratado de Montevideo de 1980", "CONVENCIDOS de la necesidad de promover el desarrollo científico y tecnológico de los Estados Partes y de modernizar sus economías para ampliar la oferta y la calidad de los bienes y servicios disponibles a fin de mejorar las condiciones de vida de sus habitantes», "REAFIRMANDO su voluntad política de dejar establecidas las bases para una unión cada vez más estrecha entre sus pueblos, con la finalidad de alcanzar los objetivos arriba mencionados».

De este modo, y si tenemos en cuenta las tres ideas fuerza del europeísmo tal como se perciben en la Declaración de Robert Schuman, del 9 de mayo de 1950, momento en el que arranca el proceso de integración en el Viejo Continente después de la Segunda Guerra Mundial, esto es, "la paz entre los europeos», "el buen gobierno democrático» y "el bienestar socioeconómico de los pueblos», en el Preámbulo del MERCOSUR sólo encontramos la apelación al bienestar socioeconómico de los pueblos en función de la una mejor integración de los mercados, pero no se hace mención a que dicho proceso debería tener otras dos grandes ideas fuerza fundamentales, es decir, la paz entre los pueblos (cerrando definitivamente el enfrentamiento entre estos países, cuyo momento más terrible fue la Guerra de la

\footnotetext{
40 «Mensaje del canciller nacional, embajador Eladio Loizaga: por los 25 años del MERCOSUR», en EDICIÓN ESPECIAL: Homenaje por los 25 años de la firma del Tratado de Asunción, op. cit., p. 14.
} 
Triple Alianza, que, entre 1864 y 1870, enfrentó a Argentina, Brasil y Uruguay contra Paraguay, con unos costos, sobre todo demográficos para Paraguay, inconmensurables y muy difíciles de superar y olvidar $)^{41}$, y la consolidación de la democracia representativa.

Sólo años más tarde, a la hora de valorar el proceso de integración del MERCOSUR, encontramos referencias explícitas a la idea fuerza de la democracia, como cuando afirma elembajador Antonio Félix López Acosta que «el Tratado de Asunción es un dispositivo político-diplomático concebido como instrumento tendiente a consolidar la democracia, [sin dejar de lado otros aspectos siempre citados, como] dar impulso a la transformación productiva y a la inserción competitiva de los países signatarios en los mercados internacionales». Según el propio Dr. López Acosta, los cuatro países que conformaron en su origen el MERCOSUR, «comparten una comunión de valores que encuentra expresión en sus sociedades democráticas, pluralistas, defensoras de las libertades fundamentales, de los derechos humanos, de la protección del medio ambiente y del desarrollo sustentable, así como su compromiso con la consolidación de la democracia, la seguridad jurídica, el combate a la pobreza y el desarrollo económico y social en equidad ${ }^{42}$. Finalmente, y en función de todo lo anterior, el MERCOSUR también pasó a ser considerado -lo que en sí mismo es algo fundamental y trascendente- como una "zona de paz», lo que fortaleció y consolidó el concepto de «cultura de paz». De este modo, la presente reflexión desde el punto de vista de la historia adquiere mayor importancia si cabe ${ }^{43}$.

\section{MERCOSUR: un apunte de situación}

Una vez en marcha el Mercado Común del Sur (MERCOSUR: Tratado de Asunción de

\footnotetext{
${ }^{41}$ En relación con lo anterior, puede verse, por ejemplo, MENDOZA MARTíNEZ, Hugo, "La integración regional sudamericana: el caso de Paraguay», en MARTíN DE LA GUARDIA, Ricardo y PÉREZ SÁNCHEZ, Guillermo Á. (Directores), La integración europea e iberoamericana. Actualidad y perspectivas en el siglo XXI, Navarra, Thomson Reuters Aranzadi, 2018, pp. 305-322.

42 «Evolución del proceso de integración del MERCOSUR», en EDICIÓN ESPECIAL: Homenaje por los 25 años de la firma del Tratado de Asunción, op. cit., los entrecomillados en pp. 33 y 36, respectivamente; sobre lo mismo también en pp. 45 y 49. En relación con lo anterior, en especial con lo que se refiere a los derechos fundamentales, véase MUSSO, José Antonio, «Análisis comparativo de los derechos humanos en el MERCOSUR y la Unión Europea», en MARTíN DE LA GUARDIA, R. y PÉREZ SÁNCHEZ, G. Á. (Directores), La integración europea e iberoamericana. Actualidad y perspectivas en el siglo XXI, op. cit., pp. 245-269.

${ }^{43}$ En este sentido, un punto de partida en CAETANO, Gerardo, Breve historia del MERCOSUR en sus 20 años. Coyuntura e instituciones 81991-2011), en el monográfico MERCOSUR 20 años (2011), pp. 21-71, y también dentro del mismo BOUZAS, Roberto, Apuntes sobre el estado de la integración regional en América Latina, pp. 75-85, y QUIJANO, José Manuel, EI MERCOSUR 20 años después, pp. 89-133; y SCOTTI, Luciana Beatriz (Directora), Balances y perspectivas a 20 años de la constitución del MERCOSUR, Buenos Aires, Eudeba. Universidad de Buenos Aires, 2013. Véase también CAETANO, Gerardo, «¿Hacia un nuevo paradigma integracionista en el MERCOSUR? Contextos y desafíos de la encrucijada actual», Relaciones Internacionales, no 30 (Octubre 2015 / Enero 2016) -Grupo de Estudios de Relaciones Internacionales (GERI)/UAM-, pp. 27-50, y MUSACCHIO, Andrés, "Los avatares del MERCOSUR en la crisis internacional», Ensaios FEE, Porto Alegre, v. 36, no 1 (jun. 2015), pp. 225-252.
} 
26 de marzo de 1991, suscrito -como ya sabemos- por Argentina, Brasil, Paraguay y Uruguay) ${ }^{44}$, recuérdese, un Tratado "para la constitución de un mercado común" y no «constitutivo de un mercado común $»^{45}$, que exigía -algo por el momento imposible de lograr- la puesta en marcha de prácticas económicas comunes de la mano de un banco central y de una moneda única, y de otra serie de actuaciones, en educación y cultura, hasta culminar en una única ciudadanía. De este modo, en función de los países adscritos ${ }^{46}$ y el calendario de actuaciones anunciado, aunque, como bien sabemos, fuera puro voluntarismo, el MERCOSUR «fue visto como la iniciativa de integración más notable en la región», aunque "su agenda de integración institucional era incluso de menor nivel que los mecanismos de integración de otras regiones de la zona, dado que no abarcó la creación de instituciones supranacionales ${ }^{47}$. En este sentido, el MERCOSUR respondería, según el embajador Antonio Félix López Acosta, a las características de un "Mercado Común Imperfecto» ${ }^{48}$.

En el calendario presentado en su momento, dentro del ámbito de la integración económica se establecieron tres fases principales: (1) un área o zona de libre comercio (que debía estar plenamente operativa en 1991); (2) una unión aduanera (pensada para 1995), pero aún no lograda, y (3) un mercado común (objetivo a lograr en 2006), todavía pendiente

\begin{abstract}
44 «A finales del siglo XX, el universo entero se vio conmovido por la caída del muro del imperialismo comunista, así como la formación de grandes bloques, fundamentalmente económicos, en muchas partes del mundo, y en América del Sur se inició el proceso de integración que posteriormente fue denominado Mercado común del Sur (Mercosur). (...). La creación del MERCOSUR abrió una página histórica en la América Latina. El desafío de la integración subregional responde a una manifestación de deseos de tendencia globalizante, promotora de profundas y radicales transformaciones en las relaciones internacionales, que apuntan a ese camino como vía de acceso privilegiado a los países en desarrollo a los mega mercados mundiales.» LÓPEZ ACOSTA, A. F., «Evolución del proceso de integración del MERCOSUR», en EDICIÓN ESPECIAL: Homenaje por los 25 años de la firma del Tratado de Asunción, op. cit., p. 32.
\end{abstract}

${ }^{45}$ En palabras del embajador Antonio Félix López Acosta, en ibídem, p. 45.

${ }^{46}$ Como ya se ha dicho, en su origen los países que conformaron el MERCOSUR fueron Argentina, Brasil, $\mathrm{Pa}$ raguay y Uruguay, a los cuales se unieron Venezuela y Bolivia (este aún pendiente de cerrar su adhesión). El MERCOSUR cuenta con una extensión de unos quince millones de $\mathrm{km}^{2}$ (unos cuatro millones y medio de $\mathrm{km}^{2}$ tiene la UE), y casi trescientos millones de habitantes (la UE cuenta con algo más de quinientos siete millones).

${ }^{47}$ De este modo, según el embajador Antonio Félix López Acosta, el Mercado común del Sur (MERCOSUR) "puede ser definido como un Tratado de Libre comercio Internacional, desarrollado a través de un ambicioso programa de integración económica (...).» "Evolución del proceso de integración del MERCOSUR», en EDICIÓN ESPECIAL: Homenaje por los 25 años de la firma del Tratado de Asunción, op. cit., p. 35.

${ }^{48} \mathrm{Ibidem}$, p. 47. En efecto, siguiendo al Dr. López Acosta, lo que sucede es que «existen imperfecciones importantes en la estructura misma del Tratado Asunción de 1991 que tocan los 3 aspectos: jurídico, económico y político». Desde el punto de vista jurídico: «las distintas formas de internalizar los Tratados Internacionales en los Países Miembros (sistema monista o dualista) hacen que no exista la posibilidad de emprender reales política comunes ni a nivel supranacional ni a nivel intergubernamental». Desde el punto de vista económico: «la importante (demasiado elevada) dependencia de los Estados parte (en particular Paraguay) de los ingresos de aranceles exteriores (...) y la voluntad de los países miembros de proteger a sus propios productos hace que el Tratado prevea un sinnúmero de excepciones (...) tanto a nivel del sistema arancelario a aplicar sobre las mercancías y servicios, cuanto a nivel de la aplicación efectiva del Arancel Exterior». Desde el punto de vista político: «la posición hegemónica de los dos grandes a todos los niveles (población, dimensión territorial, PIB, etc.) y la posición país "pequeño" (de menor dimensión económica) [de Paraguay] junto con Uruguay, la que se ve sometida a su "mediterraneidad", hace que existan asimetrías importantes que no les permiten, por ser los más vulnerables, hacer valer sus puntos de vista en las negociaciones internacionales y en las decisiones tomadas a nivel regional. Estas condiciones dan origen a tener que afrontar en el seno del MERCOSUR un desequilibrio permanente y estructural importante a todos los niveles». Ibidem, pp. 47-48. 
de establecerse en función de los escasos avances en las dos fases anteriormente reflejadas. Sobre la debilidad de dichos proceso, nadie mejor que el embajador Félix López Acosta, cuando escribe, a propósito del vigésimo quinto aniversario del Tratado de Asunción, que hasta el momento «no se ha podido perfeccionar decididamente los esquemas trazados, como son la Zona de Libre Comercio y la Unión Aduanera, que son los primeros estadios que deben ser cumplidos para luego finalmente llegar a la conformación total del Mercado Común ${ }^{49}$.

La integración institucional, por su parte, podemos señalar que se puso en marcha en 1994, en el momento de la firma del Tratado de Ouro Preto ${ }^{50}$, teniendo como modelo a la Unión Europea. Así se establecía la creación de un Consejo del Mercado Común -CMC- (una especie de Consejo Europeo, por tanto, la institución de rango superior más importante), un Grupo del Mercado común -GMC- (una especie de Comisión Europea, que dirige la actividad del día a día) y la Comisión de Comercio -CC- (encargada de los instrumentos para la debida actuación comercial), instituciones, que al conformar los órganos de decisión del MERCOSUR, están asistidas por toda una serie de grupos de expertos sectoriales.

Pero la realidad ha demostrado que dentro del MERCOSUR ni siquiera se puede hablar de un operativo y eficaz marco de actuación intergubernamental, y muchísimo menos supranacional (dada la falta homogeneidad económica, sin moneda común, sin corte de justicia, sin tribunales arbitrales, etcétera), motivo por el cual todavía está muy lejos de avanzar hacia una integración del tipo de la realizada por las Comunidades Europeas, las que después de lograr un mercado común efectivo pasaron posteriormente a establecer una unión económica y monetaria. En función de lo anterior, se puede afirmar que el MERCOSUR «no es una unión aduanera, ni siquiera de manera incompleta ${ }^{51}$; estamos, por tanto, ante un proceso de integración inacabado, que incluso pudiera ser un proyecto fallido más. En resumidas cuentas, que no se haya avanzado lo esperado desde el momento auroral de la puesta en marcha del proceso de integración es porque en el MERCOSUR «la estructura de sus órganos se acerca más a la idea de cooperación interestatal que a la noción de integración, en la que los estados son conscientes de que ceden parcelas importantes de su soberanía a favor de un órgano supranacional ${ }^{52}$.

\footnotetext{
${ }^{49}$ Ibidem, p. 31.

50 «En la Cumbre de Presidentes de Ouro Preto, de diciembre de 1994, se aprobó un Protocolo Adicional al Tratado de Asunción, el Protocolo de Ouro Preto, por el que se establece la estructura institucional del MERCOSUR y se lo dota de personalidad jurídica internacional. En Ouro Preto se puso fin al periodo de transición y se adoptaron los instrumentos fundamentales de política comercial común que rigen la zona de libre comercio y la unión aduanera que caracterizan hoy al MERCOSUR, encabezados por el Arancel Externo Común.» Ibidem, p. 37.

${ }^{51}$ Según explica embajador Antonio Félix López Acosta, «no se ha podido conformar una Zona de Libre Comercio a causa del mantenimiento de excepciones y exclusiones a la liberación arancelaria, la existencia de una variada red de restricciones no tarifarias y la fragmentación del mercado ampliado ocasionado por la no aplicación del tratamiento de "libera practica" a la importaciones de terceros que hayan pagado los derechos de aduana fijados en el arancel exterior común. (...). Reconocidas estas insuficiencias por los actores, se ha dado en tildar al mecanismo en funcionamiento como una "unión aduanera imperfecta".» Ibidem, p. 50.

52 Ibidem, p. 69.
} 


\section{La UE y el MERCOSUR ante la negociación del Acuerdo de Asocia- ción (AdA)}

Para facilitar las negociaciones entre la Unión Europea y los diferentes procesos de integración iberoamericanos, pensando sobre todo en el MERCOSUR, se puso en marcha a partir de la Cumbre de Río de 1999 una "Asociación Estratégica Birregional» ${ }^{53}$ con el objetivo de establecer una serie de Acuerdos de Asociación (AdA). Lograr dichos AdA demostró ser una tarea complicada, en especial con el MERCOSUR, motivo por el cual los primeros Acuerdos que rubricó la UE fueron con México ${ }^{54}$ en el año 2000, con Chile ${ }^{55}$ en 2002 y, casi una década después -como ya sabemos- con el Sistema de Integración Centroamericana (SICA), que data de 2010, y en el cual en 2013 entró en vigor uno de sus tres pilares, el Pilar Comercial. Sólo a partir de la Cumbre de Madrid de 2010, bajo la presidencia rotatoria de España de la UE, se relanzaron las negociaciones con el MERCOSUR, y se alcanzaron sendos tratados comerciales con Colombia y Perú. Lo anterior venía a demostrar el interés de la Unión Europea por Iberoamérica, algo por lo que venía pugnado España sin descanso en el conjunto de la UE.

El interés de la Unión Europea por establecer relaciones con el MERCOSUR puede observarse en que, incluso antes de la cumbre de Río, ya citada, el 15 de diciembre de 1995 se firmó en Madrid un Acuerdo Marco Interregional de Cooperación (AMIC) ${ }^{56}$ entre ambas organizaciones regionales, aún vigente. Pocos años después, en 1999, se decidió impulsar entre la UE y el MERCOSUR un AdA, pero el desarrollo de las negociaciones no logró consolidarse en algo duradero, motivo por el cual en 2004 se dieron por canceladas. Sin embargo, un año después, ambas partes decidieron retomar el trabajo conjunto. Así las cosas, en 2007 la UE le propuso a Brasil una asociación estratégica, y años más tarde, en 2010, de la mano de la voluntad negociadora de España las negociaciones entre la UE y el MERCOSUR volvieron a estar operativas, con la celebración de rondas de trabajo. Una vez reactivadas las negociaciones en la cumbre de Madrid, era básico priorizar el proceso y evitar bloqueos por cuestiones de menor importancia, para lo cual se hacía necesario encontrar espacios (trasversales) para la cooperación, en materia de cooperación energética, temas medioambientales, materia educativa, que tienen cabida también en el Acuerdo de Asociación al que se

\footnotetext{
53 «Las relaciones birregionales iniciaron su andadura en el escenario internacional de la guerra fría, con los conflictos centroamericanos y los procesos de transición democrática de los años ochenta; se adaptaron al nuevo escenario de la posguerra fría, en el que junto a la consolidación de las democracias, surgieron nuevos intereses económicos y ambas regiones trataron de afirmar sus respectivos proyectos de integración regional.» SANAHUJA, José Antonio, Hacia un nuevo marco de relaciones entre la Unión Europea y América Latina y el Caribe, Documento para la Fundación EU-LAC. A este respecto, véase también SBERRO, Stephan, «Las tres etapas de la relación estratégica birregional entre América Latina, el Caribe y la Unión Europea», pp. 38-43.

${ }^{54}$ Véase a este respecto NÚÑEZ DE PRADO CLAVELL, Sara, «Espejos enfrentados: México frente al continente americano y la Unión Europea», en MARTÍN DE LA GUARDIA, R. y PÉREZ SÁNCHEZ, G. Á. (Directores), La integración europea e iberoamericana. Actualidad y perspectivas en el siglo XXI, op. cit., pp. 325-349.

${ }^{55}$ Véase a este respecto RUBILAR LUENGO, Mauricio, «Chile y la integración americana: del idealismo latinoamericano al pragmatismo del regionalismo abierto», en ibidem, pp. 351-369.

${ }^{56}$ Según el Dr. López Acosta, dicho Acuerdo, en el ámbito de la Política Comercial del MERCOSUR es todavía hoy en día «un referente importante de actuación unida frente al exterior de los Estados Parte». "Evolución del proceso de integración del MERCOSUR», en EDICIÓN ESPECIAL: Homenaje por los 25 años de la firma del Tratado de Asunción, op. cit., p. 70.
} 
aspira; en definitiva, se intentaba salvar el proceso negociador puesto en marcha con tantas dificultades.

Sin embargo, como sabemos, el avance de las negociaciones nunca dejó de ser problemático, dado el nivel desigual entre ambos actores y los intereses distintos que cada cual aspiraba a lograr. Para el MERCOSUR, el objetivo central «estaba enfocado en el comercio de bienes y especialmente en el comercio de productos agropecuarios", mientras que las aspiraciones de la UE no estaban centradas sólo en la «apertura del mercado de bienes industriales», sino que se ponía el foco "en la liberalización del comercio de servicios y de compras gubernamentales (con énfasis en el mercado de Brasil), en el tratamiento de sus inversiones y en la aceptación de nuevas reglas de protección de los derechos de propiedad intelectual (DPI)». De este modo, la disparidad en los objetivos y la escasa o nula capacidad de las partes para flexibilizar sus posturas en la mesa de trabajo enturbiaron de manera reiterada y duradera, como sabemos, el proceso negociador en curso.

Con la cabeza de playa que significaba la alianza establecida con Brasil, en un momento dominado por la situación de crisis económica y financiera mundial, la UE, a través de la Comisión Europea, marcó como objetivo «la reanudación de las negociaciones con el MERCOSUR», lo que ocurrió durante el desarrollo de la VI Cumbre UE-ALC, celebrada en Madrid en mayo de 2010, como ya se ha dicho más arriba. No obstante, entre los estados miembros de la UE surgió en este momento una controversia en relación con la reactivación del proceso negociador con el MERCOSUR: con Francia al frente, dicha reactivación también era puesta en cuestión por estados miembros como Irlanda, Grecia, Hungría, Austria, Luxemburgo, Polonia y Finlandia, controversia a la que se sumaron grupos de presión vinculados al sector agropecuario comunitario. En todo caso, la controversia no logró frenar los acuerdos firmados en la Cumbre de Madrid que venían a establecer "un nuevo paradigma» por parte de la UE y una nueva inserción internacional, en la que Iberoamérica volvía a ser parte de la agenda europea, como se demostró con la firma del Acuerdo de Asociación con América Central -con el Sistema de Integración Centroamericano (SICA) - más Panamá, ya mencionado.

El proceso impulsado en la Cumbre de Madrid demostraba que la situación en la UE era distinta del momento del parón negociador en 2004. En efecto, en ese año se había cerrado la primera fase de ampliación al Este con la incorporación de ocho nuevos países (más Chipre y Malta): la Europa de los 25 llegó a los 27 en 2007 con la incorporación de los dos países restantes de la antigua Europa sovietizada ${ }^{57}$ (Ios 8 primeros fueron: República Checa, República Eslovaca, Polonia, Hungría, Eslovenia, Estonia, Letonia y Lituania, y los dos restantes: Rumania y Bulgaria); en 2013 se incorporó Croacia conformando la UE de 28. Así era la nueva UE la que inauguraba un nuevo proceso negociador con el MERCOSUR para intentar establecer el Acuerdo de Asociación tanto tiempo demorado.

Así las cosas, y en función de lo anterior, entre 2010 y 2015 tuvo continuación el desarrollo de las negociaciones UE-MERCOSUR. Del 29 de junio al 2 de julio de 2010 se reunió el Comité de Negociaciones Birregional (CNB): esta nueva etapa de la negociación presentaba

\footnotetext{
${ }^{57}$ Véase a este respecto PÉREZ SÁNCHEZ, Guillermo Á., "La "nueva Europa”: de la caída del comunismo a la integración en la Unión Europea», en FORNER, Salvador (Ed.), La construcción de Europa. De las "guerras civiles» a la «unificación», Madrid, Biblioteca Nueva. Instituto Alicantino de Cultura Juan Gil-Albert, 2007, pp. 191-217.
} 
"un esquema de dos velocidades», con el establecimiento de marcos normativos y la subsiguiente preparación y presentación de ofertas negociadoras. A partir de lo anterior, el CNB volvió a reunirse del 11 al 15 de octubre de 2010 en Bruselas; y en Asunción, en mayo de 2011; en julio, en Bruselas; en noviembre, en Montevideo; en marzo de 2012, de nuevo en Bruselas y en octubre en Brasilia. Llegados a este momento (sin que todavía se hubiera producido el necesario intercambio de ofertas por ambas partes), los países miembros del MERCOSUR comenzaron a explicitar sus distintos puntos de vista en relación con el proceso negociador: mientras que Brasil, Paraguay y Uruguay apostaban por la presentación de ofertas lo antes posible y cerrar de manera inmediata el AdA, Argentina, por su parte, se mostraba reacia a ello.

Siguiendo con la evaluación del proceso negociador que nos ocupa, podemos señalar que en enero de 2013 se reunieron en Santiago de Chile los jefes de Estado y de Gobierno de la Comunidad de Estados Latinoamericanos y Caribeños (CELAC) ${ }^{58}$ y de la Unión Europea, en el marco de la I Cumbre CELAC/UE. En esta reunión se hicieron visibles de nuevo las posturas encontradas entre los estados miembros del MERCOSUR, y ello nuevamente paralizó el avance de las negociaciones UE-MERCOSUR, aunque los países pro-AdA no dejaron de presionar al Gobierno argentino para intentar persuadirle de que cerrarse a la negociación de manera permanente podría llevarle al «aislamiento dentro del bloque, poniendo en jaque la tan valorada integración sudamericana».

Finalmente, de las ofertas nacionales se debía llegar a la oferta de bloque por parte del MERCOSUR, en la etapa que anunciaba el «proceso de consolidación», en julio de 2014. En el primer semestre de 2015 era Brasil quien debía ejercer la presidencia de MERCOSUR, y se esperaba llegar a un acuerdo para «invitar» a la UE a seguir negociando. Pero en ese momento todavía no se veía la luz al final del túnel. Así las cosas, el proceso de negociación entraba en un nuevo plazo para las partes, según el cual, éstas tenían el último trimestre de 2015 para proceder al intercambio de ofertas. Según los analistas, este último plazo debería ser visto como "una nueva oportunidad» para llevar a buen puerto el proceso negociador, pero los expertos también consideraban que cerrar con éxito el AdA de manera inmediata a finales de 2015 no parecía posible. En efecto, para octubre de 2015, no se había dado carta de naturaleza a lo acordado por los presidentes de los estados parte del MERCOSUR, ya que en el párrafo 45 del comunicado de la cumbre de Caracas del 29 de julio de 2014, se afirmaba que «la oferta del MERCOSUR se había conformado y que el bloque esperaba que la UE pudiera contar con su correspondiente oferta para poder fijar una fecha para llevar a cabo la entrega simultánea de las ofertas ${ }^{59}$.

Llegados a este punto parecía evidente que la negociación presentaba intereses encontrados en ambas uniones regionales. Así las cosas, se podía afirmar, en lo que respecta a la UE, que el Acuerdo de Asociación (AdA) con el MERCOSUR había dejado de ser relevante dentro de «la agenda de negociaciones comerciales» comunitarias, en función, sobre todo, del desconocimiento del «alcance y contenido de la oferta del MERCOSUR de desgravación

\footnotetext{
${ }^{58}$ La CELAC fue creada el 23 de febrero de 2010 en la Cumbre de la Unidad de América Latina y el Caribe, en México, y en diciembre de 2011 en la Cumbre de Venezuela quedó constituida definitivamente. La I Cumbre de la CELAC se celebró en Chile en enero de 2013. La CELAC es un organismo intergubernamental (heredero del Grupo de Río y la CALC) que promueve la integración y desarrollo de los países latinoamericanos y caribeños.
}

${ }^{59}$ Cfr. Comunicado conjunto de los Presidentes del MERCOSUR: Caracas, Venezuela, 29-VII-2014. 
del comercio de bienes", tal como explicaba la Comisaria de Comercio de la UE, sin olvidarnos de otras cuestiones que ocupan a los responsables de la Unión Europea, como son, entre otras, la evolución del Acuerdo de Asociación Transatlántica sobre Comercio e Inversiones (el TTIP, por sus siglas en inglés), las relaciones con la República Popular de China o la situación del conflicto entre Ucrania y la Federación Rusa, que tanto preocupa en Bruselas. Por la parte sudamericana, para países como Uruguay y Brasil, sin olvidarnos de Paraguay, el incentivo de las relaciones con la Unión Europea seguía siendo prioritario. Fue Paraguay, en concreto, en el ejercicio de sus funciones como presidente Pro Tempore (PPT) del MERCOSUR para el segundo semestre de 2015 , el responsable de mantener «vivas» las negociaciones en pos del AdA. En este momento debemos resaltar el cambio de orientación que fue previsible se produjera en Argentina con el nuevo Gobierno del presidente Macri, y que de la ambigüedad de los últimos tiempo pasó a impulsar también la negociación que llevó finalmente al Acuerdo de Asociación con la UE.

Para situarnos en el escenario del proceso en marcha, debemos recordar que en junio de 2015 los ministros de Asuntos Exteriores del MERCOSUR se reunieron con la comisaria de Comercio de la UE, Cecilia Malmström, en el marco de la Cumbre de la Comunidad Económica de América Latina y el Caribe (CELAC) que se celebró en Bruselas. En dicha Cumbre UE/CELAC, Brasil, al frente de la PPT del MERCOSUR, esperaba impulsar definitivamente la negociación del AdA con la UE, pero todo quedó en buenas palabras por ambas partes. Sin embargo, sobre ello volvió a referirse la PPT de Paraguay, asumida una ver cerrada la Cumbre de Brasilia, del 17 de julio de 2015, al establecer dicho proceso de negociación como una de las «prioridades del semestre». De este modo, el 18 de agosto se celebró una reunión técnica interna de los equipos negociadores del MERCOSUR «con el objetivo de revisar y mejorar la cobertura del comercio de bienes para acercarla al $90 \%$ del total (proporción exigida por la UE)». Para avanzar en el proceso, el 1 de octubre de 2015 se celebró en Asunción una nueva reunión de nivel técnico, pero, en este caso, ya entre ambas delegaciones, la del MERCOSUR y la de la UE. En relación con lo anterior, y según las declaraciones del embajador Rigoberto Gauto Vielman, Coordinador Nacional del Grupo MERCOSUR por Paraguay, «la información recogida de los negociadores europeos fue auspiciosa en relación a la oferta que harán efectiva en el mes de noviembre de 2015». Sin embargo, dicha oferta comunitaria finalmente no se materializó, y se dejó pendiente hasta mejor ocasión, por la oposición de algunos países comunitarios ${ }^{60}$.

\footnotetext{
${ }^{60}$ En efecto, según informó el 27 de noviembre de 2015 en Bruselas a EFE, el secretario de Estado de Comercio español, Jaime García-Legaz, entre estos países estaba Francia opuesta «a que la Unión Europea comience el esperado primer intercambio de ofertas comerciales con el Mercosur dentro del Acuerdo de Asociación que esas dos potencia negocian desde hace años», al parecer por la "falta de ambición del Mercosur». En sus declaraciones, García-Legaz explicó que, no obstante, ha quedado claro, en el marco del Consejo de Ministros de la UE, que "hay una mayoría amplísima de estados miembros a favor de intercambiar ofertas» con el MERCOSUR, países como España, Alemania, Italia, Reino Unido o Portugal «apoyamos claramente la negociación con Mercosur». En relación con lo anterior, el secretario de Estado español de Comercio "recordó que la decisión de empezar ese intercambio la tiene que tomar la Comisión: institución encargada de negociar en nombre de los Veintiocho los acuerdos comerciales. La Comisión lo que hace es escuchar a todos los estados miembros y luego tomar una decisión". Jaime García-Legaz también comentó a EFE lo que puede suponer de positivo para el MERCOSUR y el propio proceso negociador la actuación del nuevo Gobierno argentino del presidente Macri, dado que éste «ya ha anunciado que una de sus prioridades máximas en política exterior, y en particular en política comercial», es el acuerdo entre UE y MERCOSUR.
} 
En la cumbre del MERCOSUR, celebrada el 21 de diciembre de 2015 en Asunción del Paraguay, la primera a la que asistía Mauricio Macri poco tiempo después de tomar posesión de la presidencia de la República Argentina ${ }^{61}$, sus apuestas con respecto al proceso de integración fueron asumidas ${ }^{62}$. Debemos recordar que el mandatario argentino no dudaba a la hora de poner sobre el tablero de las relaciones regionales e iberoamericanas en su conjunto su aspiración de concretar lo que se podría denominar como una «nueva actitud en MERCOSUR». En este sentido, Macri afirmó, entre otras cosas, que pediría la aplicación de la cláusula democrática para Venezuela en el ámbito de MERCOSUR (cláusula que data de 1998, firmada en el marco del Protocolo de Ushuaia) ${ }^{63}$, y que, además, no cejaría en su esfuerzo hasta alcanzar el Acuerdo de Asociación tantos años pospuesto entre el MERCOSUR y la Unión Europea (UE), sin dejar de lado la necesaria apertura del MERCOSUR a la Alianza del Pacífico (organización regional compuesta -como ya sabemos- por Chile, Perú, Colombia y México, con Costa Rica y Panamá como países candidatos) ${ }^{64}$.

\begin{abstract}
${ }^{61}$ «Mauricio Macri consiguió el 22 de noviembre un vuelco político monumental en Argentina, impensado apenas dos meses antes. Pero al nuevo presidente no le sobra tiempo para celebrar. Hereda una economía estancada, abrumada por las urgencias, y le toca desplegar el ambicioso programa de transformaciones que prometió en la campaña sin contar con mayoría en ninguna de las dos cámaras legislativas. (...). Proclamó su intención de retomar relaciones estrechas con Estados Unidos y la Unión Europea. (...). Para que se note bien claro el viraje, Macri elegió hablar claro y fuerte sobre el chavismo. Una de sus primeras promesas como presidente electo fue anunciar que reclamará al Mercosur la aplicación de la cláusula democrática para expulsar a Venezuela del bloque a raíz de la detención de opositores y otras violaciones de los derechos humanos cometidas por el Gobierno de Nicolás Maduro. (...) Macri mira con simpatía la Alianza del pacífico. Siente una afinidad ideológica y de gestión con los gobiernos de Colombia, Chile, Perú y México. Y promueve que el Mercosur complete de una vez las negociaciones de libre comercio con la Unión Europea, estancadas en gran medida por el desinterés del Gobierno kirchnerista. (...).» RODRÍGUEZ YEBRA, Martín, «El nuevo gobierno de Macri», Papeles faes [edición digital], no 183 (4/12/2015), pp. 2 y 9.
\end{abstract}

${ }^{62}$ Comunicado conjunto de la presidenta y los presidentes de los estados partes del MERCOSUR [XLIX Reunión Ordinaria del Consejo del Mercado Común: Cumbre de Asunción, del 21 de diciembre de 2015]: punto 4. «Reiteraron su firme compromiso con el MERCOSUR, destacando que sus objetivos deben orientarse a profundizar la integración y el desarrollo de los pueblos, la consolidación de la democracia, la plena vigencia de las instituciones democráticas y el respeto de los derechos humanos y de las libertades fundamentales, que son condiciones esenciales para la vigencia y evolución del proceso de integración.», punto 9. "Coincidieron en el interés de convocar en el breve plazo una reunión de alto nivel entre el MERCOSUR y la Alianza del Pacífico a fin de abordar temas de interés común.», punto 10. "Se congratularon por los avances alcanzados en el ámbito de otros esquemas de integración (...). En este sentido, destacaron la importancia de continuar con los trabajos de articulación entre el MERCOSUR y otros foros, en aras de seguir fortaleciendo la integración de la región y su proyección en el escenario internacional.» A este respecto, véase también «La cumbre de Asunción y el rumbo del Mercosur», Notas. Periodismo popular [edición digital], 22-XII-2015.

${ }^{63}$ Así las cosas, el 2 de diciembre de 2016 se anunciaba que Venezuela había sido suspendida como estado miembro del Mercosur (a través de la agencia Reuters haciéndose eco de una fuente del Gobierno de Brasil, aunque según una fuente del Gobierno argentino dicha decisión se tomará el próximo 14 de diciembre en una reunión de ministros de Asuntos Exteriores): «Brasil, Argentina, Paraguay y Uruguay han decidido suspender temporalmente la participación de Venezuela en la organización regional por incumplir sus obligaciones en materia económica, migratoria y de Derechos Humanos.» «Venezuela, expulsada de Mercosur», $A B C$ [edición digital], 2-XII.2016.

${ }^{64}$ Para ciertos analistas, lo que pretendía Macri significaba «un giro de 180 grados hacia el liberalismo para el que necesitará el acuerdo de Brasil, el socio clave»: El País [Edición digital], 30-VI-2016. Véase a este respecto MARTNER, Gonzalo D., «Mercosur y la Alianza del Pacífico, ¿convergencia?», Economía Exterior, ํo 77 (Verano 2016), pp. 49-56. 


\section{0. ¿Estamos en este momento ante el final tanto tiempo esperado de las negociaciones del AdA entre el MERCOSUR y la UE, un acuerdo «tan lejos, tan cerca»?}

Como era de esperar, el Gobierno de Macri procedió a reactivar el proceso de negociaciones entre el MERCOSUR y la Unión Europea. Para los analistas internacionales, estamos ante «una fecha importante [el 20 de marzo de 2017] en las relaciones entre el Mercosur y la Unión Europea. Ese día, por primera vez desde 2012, negociadores de ambos bloques se reunirán en Buenos Aires para avanzar en un acuerdo comercial que lleva años de demora. La expectativa de Argentina, Brasil, Paraguay y Uruguay es que haya un entendimiento este mismo año, al menos en lo que concierne al marco político. Pero el optimismo sudamericano puede chocar con la lista de prioridades de Europa, que está cerca de alcanzar un acuerdo comercial con Japón. Las conversaciones con el Mercosur deberán resolver los puntos que han hecho fracasar hasta ahora cualquier entendimiento, sobre todo los relacionados con la demanda americana en cuestiones agrícolas y las europeas en el derecho del uso de patentes y el libre acceso de sus empresas a las licitaciones públicas de los países americanos que integran el bloque ${ }^{65}$. En efecto, el 20 de marzo, con Argentina al frente de la presidencia de la organización regional, se ponía en marcha en Buenos Aires la XXVII reunión del Comité Birregional de Negociadores MERCOSUR-UE, con la firme voluntad, según la canciller argentina, Susana Malcorra, de consolidar el proceso de negociaciones que permita llevar a buen puerto del Acuerdo de Asociación que ambas uniones regionales pretenden establecer desde el 1 de julio de 1999, cuando entró en vigor el Acuerdo Marco de Cooperación MERCOSUR-UE. La ocasión, según los observadores del proceso, puede ser propicia, «sobre todo porque ahora ambas partes se necesitan. La política de fronteras cerradas de Donald Trump en Estados Unidos reactivó finalmente negociaciones que se encontraban demoradas desde hace años. El Mercosur, y sobre todo México, y Europa necesitan estimular mercados que le permitan colocar sus productos ante una eventual escalada proteccionista de Washington ${ }^{66}$.

En este sentido, en el encuentro celebrado entre ambas partes el 20 de abril de 2017 en Bruselas, la canciller Malcorra anunciaba avances en la negociación para establecer el AdA con la Unión Europea, y que su objetivo sería presentar dicho Acuerdo - un Acuerdo ya tantas veces «tan cerca», y tantas otras «tan lejos»- ya cerrado en la cumbre de la Organización Mundial del Comercio (OMC) que se celebrará en Buenos Aires en diciembre de 2017, o como muy tarde a principios de 2018. En palabras de Malcorra: «Con los avances logrados se podría llegar a un acuerdo final en los tiempos pensados." Comprometidos con lo anterior están también los principales dirigentes europeos, entre ellos, el presidente del Gobierno español, Mariano Rajoy, que el 23 de abril de 2017 viajaba a Brasil y Uruguay para mostrar su determinación «a que se acorten los plazos para que se pueda rubricar un acuerdo entre la UE y el Mercosur, cuyas negociaciones se retomaron el año pasado. (...) Como ejemplo de ese compromiso, las fuentes del Gobierno recuerdan que en el Consejo Europeo protagoni-

\footnotetext{
65 RIVAS MOLINA, Federico y PÉREZ, Claudio, «La Unión Europea se toma con calma las negociaciones con el Mercosur y prioriza a Japón», El País [Edición digital]. 20-III-2017.

${ }^{66}$ RIVAS MOLIAN, Federico, "La Unión Europea y el Mercosur avanzan en los "valores fundamentales" de un acuerdo", El País [Edición digital]. 23-III-2017.
} 
zado en marzo por los jefes de Estado y de Gobierno de la UE, Rajoy consiguió que sus conclusiones incluyeran un compromiso expreso para impulsar esa negociación. También en la reunión que mantuvo en febrero en Madrid con el presidente de Argentina, Mauricio Macri, Rajoy expresó su convicción de que "en un tiempo no demasiado largo" será posible ese acuerdo y garantizó que España pondrá todo su empeño y hará todo lo que esté en sus manos para ello» ${ }^{67}$.

Todavía en ejercicio de la presidencia Pro Tempore del MERCOSUR, el presidente de Argentina, Mauricio Macri, celebró el 12 de julio de 2017 una reunión de trabajo con el presidente de Paraguay, Cartes. En ella, este último «abogó por que el MERCOSUR retomé sus objetivos fundamentales y se constituya en factor básico para la integración económica y comercial», para añadir a continuación: «Debemos desmantelar realmente las trabas que subsisten a nivel intra-Mercosur, las que aún limitan nuestro comercio. Si así lo hacemos, cumpliremos por fin el propósito fundamental del artículo primero del Tratado de Asunción, que consagra la libre circulación de bienes, servicios y factores productivos [capital y trabajo].» En función de lo anterior, también apuntó la necesidad -en la línea marcada por el presidente Macri- de impulsar finalmente las negociaciones para llevar a buen puerto el Acuerdo de Asociación -un proyecto de décadas, como recordó- con la Unión Europea, además de establecer acuerdos con la Alianza del Pacífico, entre otros ámbitos de integración ${ }^{68}$.

El 21 de julio de 2017 asumía Brasil la Presidencia Pro Tempore del MERCOSUR. Entre los aspectos tratados y restos asumidos por la presidencia brasileña para llevarlos a efecto en el segundo semestre de 2017, se destaca todo lo relativo a la negociación en vías de culminación del Acuerdo de Asociación con la Unión Europea, reto heredado de la presidencia Pro Tempore argentina del semestre anterior. En este sentido, la organización regional sudamericana sigue comprometida a «cerrar al menos un texto de consenso con la UE a más tardar en diciembre, una ambición que coincide con las señales enviadas desde Bruselas. "Ante las presiones proteccionistas que perduran en diferentes regiones, la razón recomienda resistir el aislamiento e insistir en los procesos de integración" [en palabras del presidente de Brasil, Michel Temer]». Como resaltaron los analistas, si dichas previsiones se mantienen en las distintas citas a la que obligaba el calendario de encuentros establecido entre ambas uniones regionales, era posible que en diciembre de 2017 se tuviera sobre la mesa un texto fruto del común acuerdo de las partes, aunque, según señalan los expertos «de ninguna manera será el acuerdo definitivo, sobre todo en lo relacionado al comercio. "Tenemos un texto de negociación común lleno de paréntesis y corchetes, pero es un texto de negociación. Y esperamos por lo menos llegar a un acuerdo político, un acuerdo que deberá ser beneficioso para los dos lados. Tenemos un empeño muy grande en acceder al mercado europeo de productos agrícolas", dijo el canciller de Brasil Aloysio Nunes [pero, como sabemos la "cuestión agrícola» ya de antiguo es uno de los escollos de la negociación, debido, sobre todo, ala recelo de Francia]. Temer pidió que "el lado europeo presente una oferta adecuada de acceso a productos agrícolas, un aspecto crucial para el acuerdo equilibrado que buscamos" ${ }^{69}$.

\footnotetext{
${ }^{67}$ Según informa EFE, y recoge Eldiario.es: 23-IV-2017.

${ }^{68}$ Cfr. La Nación [Edición digital], 13-VII-2017.

${ }^{69}$ Cfr. RIVAS MOLINA, Federico, "Cumbre del Mercosur en Argentina», El País [Edición digital], 21-VII-2017.
} 
No obstante, se cumplieron las previsiones más negativas y al terminar 2017 el texto que debía alumbrar el definitivo Acuerdo de Asociación entre la UE y el MERCOSUR no había prosperado por enésima vez. De este modo, los negociadores de ambas uniones regionales se citaban para intentar concluir el Acuerdo tanto tiempo pospuesto a lo largo del primer semestre de 2018. En este sentido, sin embargo, las esperanzas se vieron de nuevo defraudadas, desmintiendo las previsiones tanto de la parte europea - No sé si será la última ronda de negociaciones, pero cada vez que nos reunimos estamos más cerca», en palabras pronunciadas en abril de 2018 por la comisaria de Comercio de la Unión Europea, Cecilia Malmström-, como de la parte iberoamericana - «el Mercosur nunca estuvo tan cerca de un acuerdo comercial con la Unión Europea», según declaraciones del secretario de Comercio Exterior de Brasil, Abrao Arabe Neto, también del mismo mes de abril-, al cerrarse dicho semestre sin atisbo de acuerdo entre la partes.

Durante la ronda de negociaciones, entre el MERCOSUR y la UE, celebradas del 4 al 8 de junio de 2018 en Montevideo (Uruguay), se volvieron a plantear las mismos argumentos por los equipos negociadores, comprometiéndose a redoblar los esfuerzos para alcanzar la meta propuesta, dado que las partes concernidas estaban convencidas -a la postre puro voluntarismo- de estar ante «el principio del final» del proceso para establecer el esperado AdA. Pero el proceso negociador montevideano se saldó con una nueva decepción, y, por lo tanto, sin acuerdo entre las partes. Después del verano, Christoph Leitl, presidente de Eurochambres (una unión de cámaras que agrupa a más de veinte millones de empresa europeas), expresaba claramente la posición de esta institución y apelaba a un último esfuerzo para encauzar de nuevo el proyecto de AdA, inmerso, según los analistas, en una de sus fases más críticas, y lo expresaba muy gráficamente: "Si no conseguimos el tratado Unión Europea-Mercosur, Estados Unidos nos arrollará « ${ }^{70}$. De viaje en Buenos Aires, Leitl pretendía llamar la atención de los dirigentes de los países del MERCOSUR, y especialmente de Argentina -recordando que en este país se iba a celebrar la cumbre del G-20 (que en efecto, tuvo lugar del 30 de noviembre al 1 de diciembre de 2018, siendo la primera en su género desarrollada en Sudamérica) -, dado que, a su juicio, se estaba ante la disyuntiva del "ahora o nunca», según sus palabras: "Es el momento de superar los problemas técnicos que, en realidad, son ya pocos porque el apartado agrícola está casi despejado, y hacer política de altura porque tanto la Unión Europea como el Mercosur necesitan absolutamente el acuerdo.» "Hacer política de altura», tal como pedía Christoph Leitl, para impulsar y llevar a buen puerto el AdA entre dichas uniones regionales, parecía un imposible cuando los políticos llamados a pilotar el nuevo Gobierno de Brasil (recordemos que el presidente electo Jair Bolsonaro asume el cargo el próximo 1 de enero de 2019) señalaron, en palabras de Paulo Guedes, futuro ministro de Hacienda, que, en estos momentos, el Mercosur «no es una prioridad $\rangle^{71}$. El comienzo del año no podía ser peor para los partidarios de impulsar el MERCOSUR y de establecer el tan esperado AdA con la Unión Europea, ante una frustración de sus expectativas. Pero, como veremos a continuación, los equipos negociadores de la UE y del MERCOSUR enderezaron el proceso hasta llevarlo a buen puerto.

\footnotetext{
${ }^{70}$ El País [Edición digital], 4-X-2018.

${ }^{71}$ El País [Edición digital], 30-X-2018.
} 


\section{Balance de la situación de las relaciones entre la UE, el SICA y el MERCOSUR en el momento presente}

Más allá de la situación actual en la que se encuentren las relaciones entre la UE, el SICA y el MERCOSUR, lo cierto es que los procesos de integración regional iberoamericanos siguen interesando en los foros económicos internacionales. Así en un encuentro de estas características celebrado del 11 al 12 de 2018 de octubre en Hamburgo (Alemania), se desarrolló, en la jornada dedicada al Día de Latinoamérica, una mesa redonda sobre "Alianzas comerciales latinoamericanas en el contexto Económico Global», en la que participaron representantes del SICA, del MERCOSUR y de La Alianza del Pacífico. Como se desprende de las informaciones publicadas, la cuestión «más acuciante planteada en la mesa redonda fue hasta qué punto los acuerdos de integración vigentes funcionan ${ }^{72}$.

En este sentido, y en lo que respecta al SICA, tal como lo hemos intentado explicar en el epígrafe correspondiente de este trabajo, con un Acuerdo de Asociación firmado el 29 de junio de 2012 con la Unión Europea, podemos afirmar que dicha integración centroamericana está inmersa en el proceso de potenciar los tres pilares que dan coherencia al AdA suscrito con la UE, sobre la base diálogo político, de cooperación y comercial. Sólo así, un SICA plenamente vigente podrá aspirar a mantenerse operativo en el tiempo, más allá, como ya se ha dicho, de las dificultades estructurales propias de una región en desarrollo, pero que, en consonancia con la experiencia europea, apueste por potenciar los valores de lo supranacional, en coexistencia con lo intergubernamental, como norma fundamental de su integración regional.

En cuanto a las relaciones entre la Unión Europea (UE) y el MERCOSUR, cuyo proceso de negociación para establecer un Acuerdo de Asociación parecía estar a la deriva y muy lejos de concluir de manera positiva para ambas partes, con lo cual el mensaje no puede ser más negativo: de manera inopinada todo se aceleró y, finalmente, el 28 de junio de 2019 se firmó el Acuerdo de Asociación (estratégica) entre la Unión Europea (UE) y el MERCOSUR; eso sí, a la espera de la respectivas ratificaciones por parte de los estados afectados. Así las cosas, se han invertido las tornas hacia el optimismo, pero si los avatares políticos influyeran de nuevo negativamente y no se ratificara el Acuerdo suscrito, el proyecto de integración que el MERCOSUR representa quedaría muy dañado y en una situación de aislamiento insoportable. En lo que respecta a la UE se puede decir lo mismo: después de haber logrado que la firma del Acuerdo fuera posible, no se entendería que él no fuera ratificado; en este hipotético caso, la UE pondría en cuestión su capacidad de actuación en toda Iberoamérica como impulsor de los procesos de integración regionales o subregionales, lo cual implicaría abdicar como agente internacional comprometido -en función de una cultura de paz y de buen gobierno democrático, asumida desde los momentos fundacionales-con la estabilidad política y el necesario y óptimo desarrollo socioeconómico de los pueblos ${ }^{73}$.

\footnotetext{
72 De ello trata el artículo de opinión "Tiempos revueltos en Latinoamérica» -El País [Edición digital], 2-XII2018-, firmado por Inmaculada Martínez-Zarzoso, Catedrática de Economía en las universidades de Gotinga (Alemania) y Jaume I de Castellón, y que actúo como moderadora de la mesa redonda ya citada.

${ }^{73}$ Véase a este respecto CAVIERES FIGUEROA, Eduardo, «PRÓLOGO: América Latina y la Unión Europea: un necesario proyecto de convergencias sobre las divergencias»; y también MANERO MIGUEL, Fernando, «EPÍLOGO: La Unión Europea y el Mercado Común del Sur: dos integraciones regionales complementarias ante un escenario de grandes desafíos globales e internos», en MARTíN DE LA GUARDIA, R. y PÉREZ SÁNCHEZ, G.
} 
En todo caso, y en relación con todo lo anterior, procede recordar las siguientes palabras de Eduardo Cavieres Figueroa: «En medio de tantas turbulencias, conflictos, desconfianzas, irritaciones, aún quedan espacios de humanidad, de racionalidad, de solidaridad, de buen sentido. Que lo que tanto costó construir por parte de Europa, no se diluya; y que América Latina sepa por donde debe dirigir su historia ${ }^{74}$. Esta reflexión nos debe ayudar a no dejarnos llevar por la melancolía, a seguir posicionados «en la esperanza y no en la espera», y firmes en nuestras convicciones de no caer en el pesimismo al que la realidad de los hechos no deja de empujarnos y, así, forzar el destino.

\section{Bibliografía}

ARENAL, Celestino del, "La adhesión de España a la comunidad Europea y su impacto en las relaciones entre América Latina y la Comunidad Europea», Revista de Instituciones Europeas, vol. 17 (1990), pp. 329-368.

ARENAL, Celestino del y NÁJERA, Alfonso, La Comunidad Iberoamericana de Naciones. Pasado, presente y futuro de la política iberoamericana de España, Madrid, Cedeal, 1992.

ARENAL, Celestino del y SANAHUJA, José Antonio (coords.), América Latina y los Bicentenarios: una agenda de futuro, Madrid, Siglo XXI y Fundación Carolina, 2010.

BENEGAS CRISTALDO, Gladys S., A la búsqueda de un Mercado Común: MERCOSUR. Creación de Comercio, Desviación de Comercio e Implicaciones de Políticas Públicas, Asunción, Paraguay, Centro de Publicaciones de la Universidad Católica Nuestra Señora de la Asunción, 1994.

BENEYTO, José María (Dir.) y ARGEREY, Patricia (Coord.), Europa y América Latina. El otro diálogo transatlántico, Biblioteca Nueva e Instituto Universitario de Estudios Europeos de la Universidad San Pablo CEU, Madrid, 2006.

BIDAURRATZAGA, Eduardo y ZABALO, Patxi, «Efectos potenciales del Acuerdo de Asociación con la Unión Europea sobre el desarrollo de Centroamérica», http://xivrem.ujaen.es/wp-content/uploads/2012/05/80-R-043M517.pdf.

CAETANO, Gerardo, «¿Hacia un nuevo paradigma integracionista en el MERCOSUR? Contextos y desafíos de la encrucijada actual», Relaciones Internacionales, no 30 (Octubre 2015 / Enero 2016) -Grupo de Estudios de Relaciones Internacionales (GERI)/UAM-, pp. 27-50.

CANO LINARES, Mạ Ángeles y DÍAZ-SILVEIRA SANTOS, Cintia, La acción exterior del Sistema de la Integración Centroamericana, Madrid, Editorial Dykinson, 2012.

\footnotetext{
Á. (Directores), La integración europea e iberoamericana. Actualidad y perspectivas en el siglo XXI, op. cit., pp. 21-36 y pp. 371- 395, respectivamente.

74 «Europa-América Latina: política y cultura en pasado-presente», IELAT -Documento de Trabajo- [Edición digital], no 93 (diciembre 2016), p. 30. El Dr. Eduardo Cavieres Figueroa es Premio Nacional de Historia de Chile.
} 
CAVIERES FIGUEROA, Eduardo, «Europa-América Latina: política y cultura en pasado-presente», IELAT -Documento de Trabajo- [Edición digital], no 93 (diciembre 2016).

CAVIERES FIGUEROA, Eduardo, «PRÓLOGO: América Latina y la Unión Europea: un necesario proyecto de convergencias sobre las divergencias», en MARTíN DE LA GUARDIA, R. y PÉREZ SÁNCHEZ, G. Á. (Directores), La integración europea e iberoamericana. Actualidad y perspectivas en el siglo XXI, Navarra, Thomson Reuters Aranzadi, 2018, pp. 21-36.

"Centroamérica: los retos del Acuerdo de Asociación con la Unión Europea», en Estudios y perspectivas -CEPAL (Sede Subregional México-, 102 (2008), 68 páginas.

COMISIÓN EUROPEA, «Documento de estrategia regional para América Central, 2007-2013», (Marzo 2007).

Comunicado conjunto de los Presidentes de MERCOSUR: Caracas, Venezuela, 29-VII-2014.

Comunicado conjunto de la presidenta y los presidentes de los estados partes del MERCOSUR [XLIX Reunión Ordinaria del Consejo del Mercado Común: Cumbre de Asunción, del 21 de diciembre de 2015].

EDICIÓN ESPECIAL: Homenaje por los 25 años de la firma del Tratado de Asunción, Asunción, ADEP, 2016.

EFPB 87/227 «Conclusions adopted by the Council ande the Represenattives of the Governments of the Member States Concerning the Relations with Latin America», Bruselas, 22 de junio de 1987.

GOBIERNO DE EL SALVADOR, Acuerdo de Asociación: ofreciendo oportunidades para el desarrollo, Documento explicativo del Acuerdo de Asociación entre Centroamérica y la Unión Europea, 2013.

GRANADOS, Jaime; LIZANO, Eduardo, y OCAMPO, Fernando (Editores), Un puente para el crecimiento. Oportunidades y desafíos del Acuerdo de Asociación entre Centroamérica y la Unión Europea, banco Interamericano de Desarrollo, Academia de Centroamérica y Konrad-Adenauer-Stiftung, 2009.

HURTADO, Osvaldo, "Aspectos políticos de la integración latinoamericana», Integración Latinoamericana. BID/INTAL 153 (enero-febrero 1990).

KONRAD-ADENAUER-STIFTUNG (Oficina en Costa Rica y Panamá), «El Acuerdo de Asociación entre Centroamérica y la Unión Europea», www.kas.de/costa-rica/es/pages/6207/.

"La cumbre de Asunción y el rumbo del Mercosur», Notas. Periodismo popular [edición digital], 22-XII-2015.

LÓPEZ, Aldo Centurión, MERCOSUR significa «la más grande oportunidad para ser un país desarrollado»: La dimensión MERSOSUR. Capítulo Paraguay, Asunción. Paraguay, Fondec.

LUCENA GIRALDO, Manuel, Naciones rebeldes. Las revoluciones de independencia latinoamericanas, Madrid, Taurus, 2010. 
MALAMUD, Carlos, Populismos latinoamericanos. Los tópicos de ayer, de hoy y de siempre, Madrid, Ediciones Nobel, 2010.

MANERO MIGUEL, Fernando, «EPÍLOGO: La Unión Europea y el Mercado Común del Sur: dos integraciones regionales complementarias ante un escenario de grandes desafíos globales e internos», en MARTíN DE LA GUARDIA, R. y PÉREZ SÁNCHEZ, G. Á. (Directores), La integración europea e iberoamericana. Actualidad y perspectivas en el siglo XXI, Navarra, Thomson Reuters Aranzadi, 2018, pp. 371395.

MARTÍN DE LA GUARDIA, Ricardo, "La política europea de España después de la integración en las comunidades», Cuadernos Europeos de Deusto, no 32 (2005).

MARTÍN DE LA GUARDIA, Ricardo y PÉREZ SÁNCHEZ, Guillermo Á. (Directores), La integración europea e iberoamericana. Actualidad y perspectivas en el siglo XXI, Navarra, Thomson Reuters Aranzadi, 2018.

MARTNER, Gonzalo D., «Mercosur y la Alianza del Pacífico, ¿convergencia?», Economía Exterior, no 77 (Verano 2016), pp. 49-56.

MEJÍA HERRERA, Orlando José, La Unión Europea como modelos de integración: análisis comparativo del Sistema de la Integración Centroamericana, León, Editorial Universitaria, UNAN-León, 2008.

MIRANDA, Otilio, Derecho Comunitario de América Central, Managua, Universidad Centroamericana, 2010.

MONTALBÁN, Juan Francisco, «Los cambios en la política comunitaria hacia América Latina tras la adhesión española», Tiempo de Paz, no 24-25 (1992), pp. 107-112.

MUÑOZ MACHADO, Santiago, Hablamos la misma lengua. Historia política del español en América, desde la Conquista a las Independencias, Barcelona, Crítica, 2017.

MURCIA, Walter, ODDONE, Nahuel, y RODRÍGUEZ VÁZQUEZ, Horacio, La integración centroamericana: orígenes, avances y desafíos, -Cuadernos de Cooperación Internacional y Desarrollo-, México, Instituto Mora. Universidad Iberoamericana, 2015.

MUSACCHIO, Andrés, "Los avatares del MERCOSUR en la crisis internacional», Ensaios FEE, Porto Alegre, v. 36, no 1 (jun. 2015), pp. 225-252.

OLMOS GIUPPONI, María Belén y RUBIO RÍOS, Luis Arnoldo (eds.), La adopción de políticas en el sistema de la Integración Centroamericana. Propuestas para su perfeccionamiento a la luz de la experiencia europea, Madrid, Plaza y Valdés Editores, 2011.

OTERO, Delia del Pilar, Integración Latinoamericana. Ciclos en la construcción de un proyecto fundacional, Córdoba, Alción Editorial, 2007.

PÉREZ SÁNCHEZ, Guillermo Á., "La "nueva Europa”: de la caída del comunismo a la integración en la Unión Europea», en FORNER, Salvador (Ed.), La construcción de Europa. De las "guerras civiles» a la "unificación», Madrid, Biblioteca Nueva. Instituto Alicantino de Cultura Juan Gil-Albert, 2007, pp. 191-217. 
PIÑOL, Joan, «Las relaciones españolas en Centroamérica: el período de los Gobiernos socialistas", Afers Internacionals, no 14-15 (1988), pp. 5-40.

RECONDO, Gregorio (Coordinación y Prólogo), MERCOSUR. Una historia común para la integración, Tomo I y Tomo II, Asunción, Paraguya, Multibanco SAECA, 2000.

RODRÍGUEZ YEBRA, Martín, «El nuevo gobierno de Macri», Papeles faes [edición digital], № $183(4 / 12 / 2015)$.

SANAHUJA, José Antonio y SOTILLO, José Ángel (coords.), Integración y desarrollo en Centroamérica. Más allá del libre comercio, Madrid, Instituto Universitario de Desarrollo y Cooperación, Universidad Complutense de Madrid. Los Libros de la Catarata, 1998.

SANAHUJA, José Antonio, Hacia un nuevo marco de relaciones entre la Unión Europea y América Latina y el Caribe, Documento para la Fundación EU-LAC.

SCOTTI, Luciana Beatriz (Directora), Balances y perspectivas a 20 años de la constitución del MERCOSUR, Buenos Aires, Eudeba. Universidad de Buenos Aires, 2013.

SOTO, Alfredo Mario y GONZÁLEZ, Flavio Floreal, Manual de Derecho de la Integración, Buenos Aires, La Ley, 2016.

TORRES, Jorge José, El concepto de «Integración latinoamericana». Contenido, reformulaciones y continuidades, Buenos Aires, Dunken, 2008.

TURIENZO, Raquel, Procesos de integración en Sudamérica. Un proyecto más ambicioso: la Comunidad Sudamericana de Naciones (CSN), Madrid, Instituto Universitario de Estudios Europeos de la Universidad San Pablo CEU de Madrid.

ULATE CHACÓN, Enrique y OLMOS GIUPPONI, Ma Belén, «Sistema de la Integración Centroamericana (SICA): Estructura institucional, ámbitos de actuación y perspectivas de futuro", en Cuadernos Iberoamericanos de integración, 9 (2009), 155 páginas.

VV.AA., MERCOSUR 20 años (2011).

VV.AA., Mirada Centroamericana, Ciudad de Guatemala, Universidad Rafael Landívar. Guatemala, Universidad Centroamericana José Simeón Cañas. El Salvador, Universidad Centroamericana. Nicaragua, 2017. 


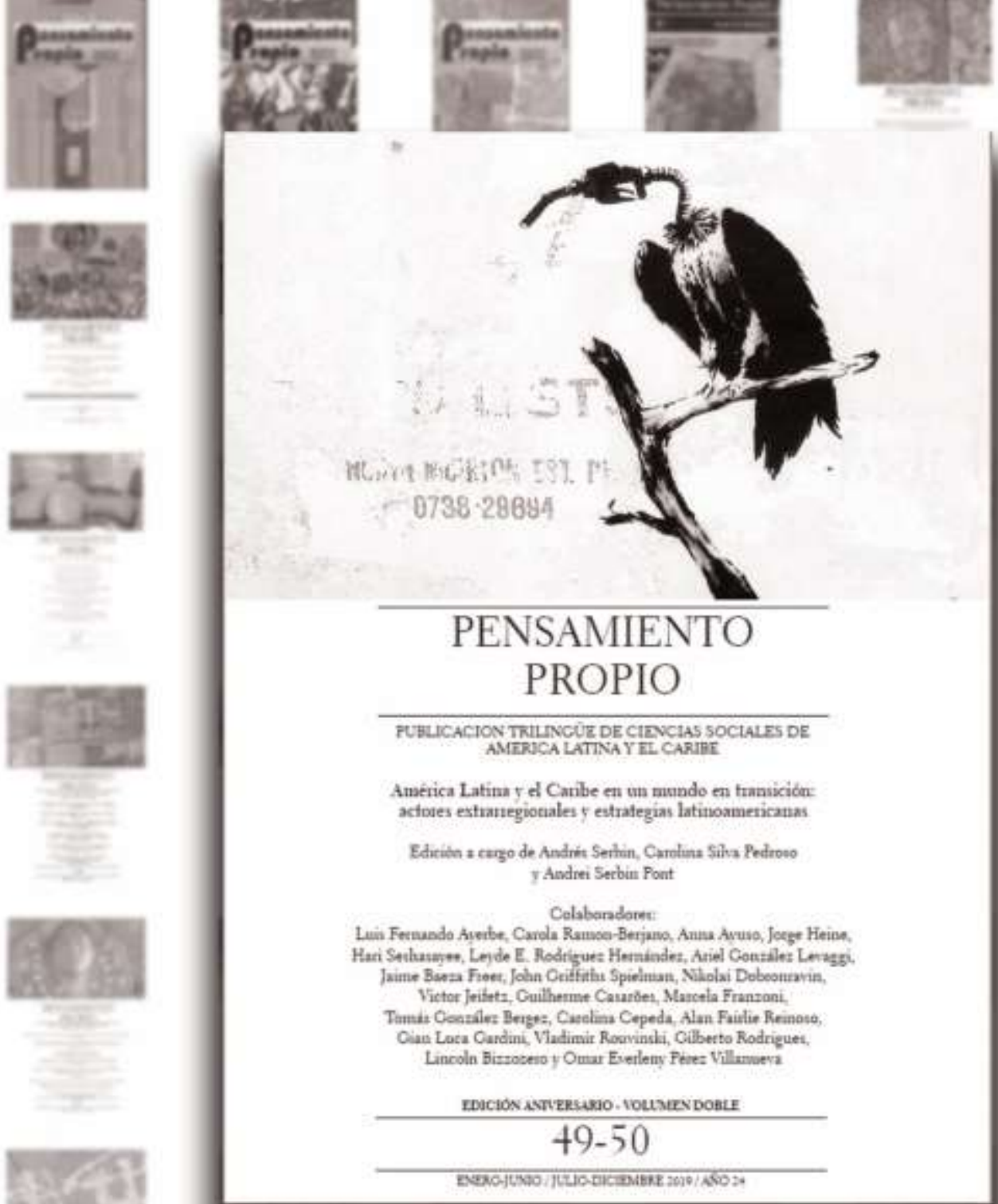

\section{YA ESTÁ DISPONIBLE EL NUEVO NÚMERO DE PENSAMIENTO PROPIO:}

América Latina y el Caribe en un Mundo en Transición: Actores Extrarregionales y Estrategias Latinoamericanas

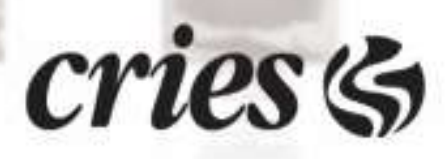

